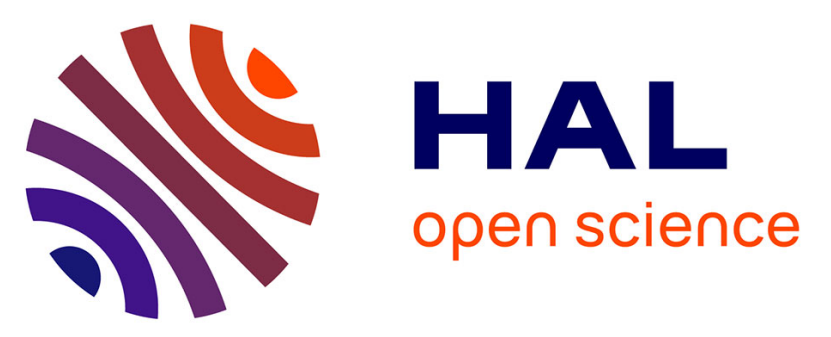

\title{
Application of Synchrotron Radiation-Computed Tomography In-Situ Observations and Digital Volume Correlation to Study Low-Cycle Fatigue Damage Micromechanisms in Lost Foam Casting A319 Alloy
} Long Wang, N. Limodin, Ahmed El Bartali, Jean-Francois Witz, Jean-Yves Buffiere, Eric Charkaluk

\section{To cite this version:}

Long Wang, N. Limodin, Ahmed El Bartali, Jean-Francois Witz, Jean-Yves Buffiere, et al.. Application of Synchrotron Radiation-Computed Tomography In-Situ Observations and Digital Volume Correlation to Study Low-Cycle Fatigue Damage Micromechanisms in Lost Foam Casting A319 Alloy. Metallurgical and Materials Transactions A, 2020, 51 (8), pp.3843-3857. 10.1007/s11661-020-05839-5 . hal-02891999

\section{HAL Id: hal-02891999 \\ https://hal.science/hal-02891999}

Submitted on 8 Jul 2020

HAL is a multi-disciplinary open access archive for the deposit and dissemination of scientific research documents, whether they are published or not. The documents may come from teaching and research institutions in France or abroad, or from public or private research centers.
L'archive ouverte pluridisciplinaire HAL, est destinée au dépôt et à la diffusion de documents scientifiques de niveau recherche, publiés ou non, émanant des établissements d'enseignement et de recherche français ou étrangers, des laboratoires publics ou privés. 
This document is a personal copy of the accepted version of the paper:

Wang, L., Limodin, N., El Bartali, A. et al. Application of Synchrotron Radiation-Computed Tomography In-Situ Observations and Digital Volume Correlation to Study Low-Cycle Fatigue Damage Micromechanisms in Lost Foam Casting A319 Alloy. Metall Mater Trans A 51, 3843-3857 (2020). https://doi-org.ressources-electroniques.univ-lille.fr/10.1007/s11661-020-05839-5

The final publication is available at link.springer.com

\title{
Application of SR-CT in-situ observations and Digital Volume Correlation to study low cycle fatigue damage micromechanisms in lost foam casting A319 alloy
}

Long Wang ${ }^{\mathrm{a}, 1}$, Nathalie Limodin ${ }^{\mathrm{a}}$, Ahmed El Bartali ${ }^{\mathrm{a}}$, Jean-François WITZ ${ }^{\mathrm{a}}$, Jean-Yves Buffiere ${ }^{\mathrm{b}}$, Eric Charkaluk ${ }^{\mathrm{a}, 2}$

${ }^{a} U n i v$. Lille, CNRS, Centrale Lille, Laboratoire de Mécanique, Multiphysique, Multiéchelle (LaMcube) UMR CNRS 9013, F-59000 Lille, France

${ }^{b}$ Laboratoire Matériaux, Ingénierie et Sciences (MATEIS), CNRS UMR5510, INSA-Lyon, 20 Av. Albert Einstein, 69621

Villeurbanne, France

\begin{abstract}
Synchrotron Radiation Computed Tomography (SR-CT) and Digital Volume Correlation (DVC) method were used to investigate the damage micromechanisms of Lost Foam Casting (LFC) A319 alloy in Low Cycle Fatigue (LCF). LCF tests with SR-CT in situ observations allow visualizing the damage evolution process in the bulk. DVC measures the mechanical fields and thus allows establishing the relations between crack initiation and propagation, mechanical fields and microstructure. Cracks initiate at and propagate along hard inclusions due to strain localizations. The damage process, i.e. crack initiation and propagation, can be considered as a series of failure events of hard inclusions under strain localizations. Pores' size, shape, location, and number were observed to have an influence on crack initiation, while the interconnected hard inclusion networks guarantee the continuous failure events of hard inclusions and thus provide crack propagation paths.
\end{abstract}

Keywords: Al-Si alloys; Low cycle fatigue; Synchrotron radiation computed tomography; In-situ; Digital Volume Correlation

\footnotetext{
*Corresponding author: Long Wang (Email:long.wang.fr@hotmail.com; Tel. +86 1520138 8702)

${ }^{1}$ Present address: Science and Technology on Reliability and Environmental Engineering Laboratory, Beijing Institute of Structure and Environment Engineering, Beijing, China

2 Present address: Laboratoire de Mécanique des Solides - UMR 7649, Ecole Polytechnique, Palaiseau cedex, France
} 


\section{Introduction}

Cast Aluminum Silicon (Al-Si) alloys, such as A319 alloy, feature high strength to weight ratio, good machinability, optimum surface finish and high electrical and thermal conductivity, and are thus widely used in automotive engine parts, such as cylinder head that is one of the key components of the engine [1]. The main role of the cylinder head is to seal the cylinders and to form the combustion chamber with pistons and cylinder block. Thus cylinder heads, especially the inter-valve zones in fire deck, undergo severe thermomechanical stresses with temperature variation from 20 to $250^{\circ} \mathrm{C}$. Accordingly, good material mechanical properties are required to adapt to the in-service conditions, in particular to the thermomechanical Low Cycle Fatigue (LCF) loading due to the engine startup and shutdown: LCF with plastic deformation in compression at high temperature and in tension at Room Temperature (RT) [2].

In automotive industry, the Lost Foam Casting (LFC) process is supplanting the traditional gravity Die Casting (DC) process to manufacture cylinder head with the aim of geometry optimization and cost reduction $[3,4]$. However, the A319 alloy cylinder heads manufactured by LFC present a coarser microstructure and a larger pore volume fraction than that manufactured by DC at faster cooling rates [5]. As the fatigue life of material depends on the microstructure, the fatigue life of LFC A319 alloy is much shorter than that of DC A319 alloy while the cyclic stress-strain behavior almost remains unchanged [1].

Studies on damage micromechanisms of Al-Si alloys have generally been focused on High Cycle Fatigue (HCF) regime [6-19]. In this case, cracks tend to initiate at large pore above a critical size and the pores location, shape, and number can also play a role [6-12]. In the absence of large pores, hard inclusions, i.e. eutectic $\mathrm{Si}$, Iron intermetallic particles and Copper containing phases, may also act as crack initiation sites [13-15,17,19]. A high iron content promotes crack initiation at iron intermetallics [16], while crack may initiate at copper containing phases at low iron level [17]. No matter where cracks initiate, they tend to propagate along hard inclusions $[14,16,18]$ although eutectic Si and Iron intermetallics are also observed to act as barriers for crack propagation $[16,18]$.

Only a few studies [1,5,20-25] on the damage micromechanisms of Al-Si alloys have been focused in LCF regime. Similar with HCF, in LCF, large pores are also considered as the most probable initiation site [1,5], and the effect of eutectic Si and iron intermetallics is highlighted in the absence of large pores [12,20-22]. However, if increasing the Fe content reduces life in HCF [16], it slightly increases life in LCF [16,22]. Besides, spheroidisation of the eutectic silicon increases the fatigue life in HCF [13], while it leads to a systematic decrease in LCF [20]. Moreover, these LCF studies, based on indirect observations such as post-mortem analysis [1,20], did not allow following 
in real time the damage evolution process and thus only provided limited evidences to conjecture the damage micromechanisms. Hence, the damage micromechanisms of Al-Si alloys in LCF are still unclear, especially for LFC Al-Si alloys with large pores and coarse microstructures.

In the same time, X-ray Computed Tomography (CT) began to be used as a 3D investigation technique. X-ray $\mathrm{CT}$ is an attractive non-destructive way to characterize the microstructure of material in bulk [26-28] and has already been used to follow damage evolution in-situ during mechanical tests in recent years [29-34].

The objective of this paper is to understand the damage mechanisms of LFC A319 alloy in LCF at Room Temperature. An experimental protocol has been developed in order to achieve this objective. Synchrotron Radiation Computed Tomography (SR-CT) was employed to follow the crack initiation and propagation in-situ in the bulk of the studied alloy during LCF tests. Compared to Laboratory Computed Tomography (Lab-CT), the phase-contrast imaging provided by SR-CT [26] allows to visualize the $\mathrm{Si}$ particles within the Al matrix. The volumetric mechanical fields were estimated by using the tomographic images acquired during the tests. Then, the relations between crack initiation and propagation, mechanical fields and the microstructures of LFC A319 alloy were established in 3D in order to understand its damage micromechanisms in LCF at RT.

\section{Material and experimental methods}

\subsection{Material}

The chemical composition of the studied A319 alloy is given in Table 1. All specimens used in this study were cut from A319 prototype cylinder heads manufactured using the LFC process; they were taken from the fire deck area (Fig. 1a) that is the most critical area.

\begin{tabular}{|c|c|c|c|c|c|c|c|c|c|c|c|c|}
\hline Si & Fe & Cu & $\mathrm{Mn}$ & $\mathrm{Mg}$ & $\mathrm{Ni}$ & \multirow{2}{*}{$\mathrm{Zn}$} & \multirow{2}{*}{$\mathrm{Pb}$} & \multirow{2}{*}{$\mathrm{Sn}$} & \multirow{2}{*}{$\mathrm{Ti}$} & $\mathrm{Cr}$ & \multicolumn{2}{|c|}{$\mathrm{Zr}, \mathrm{V}, \mathrm{P}, \mathrm{Sr}$} \\
\cline { 9 - 12 } & & & & & & & & & & & \\
\hline $\mathbf{7 . 8 5}$ & $\mathbf{0 . 3 0}$ & $\mathbf{3 . 0 5}$ & 0.19 & 0.28 & 0.018 & 0.16 & $<0.015$ & $<0.015$ & 0.098 & 0.015 & $\leqq 0.03$ & $\leqq 0.1$ \\
\hline
\end{tabular}

Table 1 Chemical composition of A319 (A1Si7Cu3) LFC alloy (wt.\%)

(a)

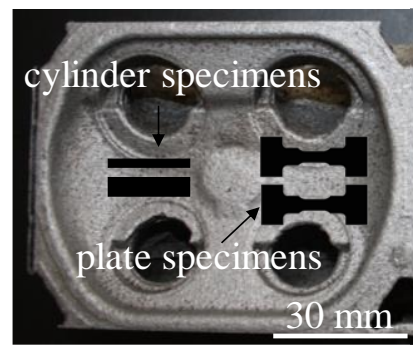

(b)

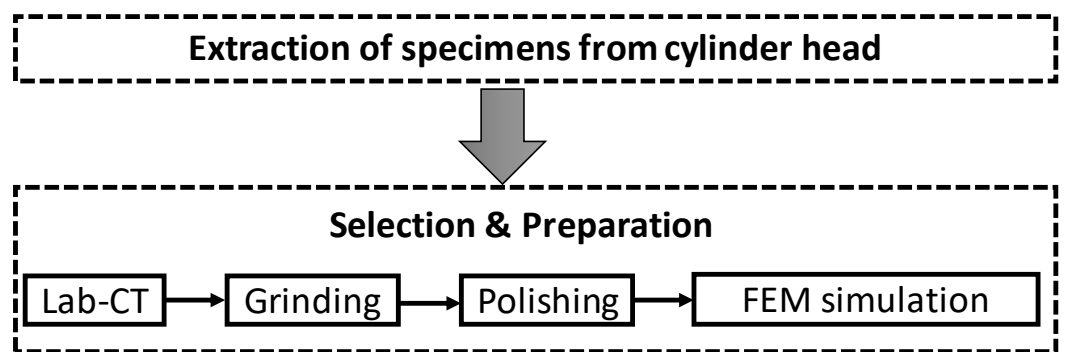

Fig. 1. (a) Extractions of specimens from cylinder head;(b) The procedure of extraction, preparation and selection of specimens. 
2D characterizations performed using Scanning Electron Microscopy (SEM) together with Energy Dispersive Spectroscopy (EDS) allowed identifying the microstructural constituents in the studied material: pores and hard inclusions including eutectic $\mathrm{Si}$, iron intermetallics and copper containing phases. They were then characterized in 3D by using Lab-CT and SR-CT [35,36]:

- The pores could be classified as either rounded gas pores and tortuous shrinkage pores.

- Hard inclusions, i.e. Si, iron intermetallics and copper containing phases, present complex coral-like interconnected network morphologies; the interconnected networks of Si and iron intermetallics extend to the whole volume; the thickness of eutectic $\mathrm{Si}$ is smaller than other hard inclusions, i.e. its average thickness is $6 \sim 18 \mu \mathrm{m}$.

The reader can refer to Ref. $[35,36]$ for the details about the 2D and 3D characterizations.

\subsection{Specimens}

Fig. 1b summarizes the procedure of extraction, preparation and selection of specimens for LCF tests. The dog-bone shaped specimens having the geometry shown in [36] were used for fatigue tests with SR-CT in-situ observations. The high resolution that is necessary to reveal hard inclusions and cracks results in a limited scan volume, thus a small size of specimen with a minimum cross-section of $2.6 \times 2.6 \mathrm{~mm}^{2}$ was employed.

Large pores are assumed to be the most critical initiation sites and surface pores are considered more critical than subsurface pores [6-10]. Thus Lab-CT was used to reveal pores in the bulk in order to select the most suitable specimens among all the extracted specimens. The chosen specimens have no large defects near their shoulders while both volume fraction and distribution of pores in the selected specimen should be consistent with that characterized in a larger sample [36]. Ten of 36 extracted specimens were selected for LCF tests with SR-CT in-situ observation by using Lab-CT (in MATEIS laboratory, Lyon, France) in the fast scan mode, i.e. the scan lasts about 6 minutes, at a 5 $\mu \mathrm{m}$ voxel size. The height of the tomographic image is 1400 pixels, i.e. $7 \mathrm{~mm}$, so that it includes the $4 \mathrm{~mm}$ of the specimen's gauge length. In order to check if the selected small size specimens are representative for the studied material, each specimen was analyzed in 3D for comparisons of pores between the selected specimen and the large size sample in [36]. Then, a scan with a higher resolution (voxel size $\sim 1.6 \mu \mathrm{m}$ ) but in a smaller volume (reduced height) was taken at the beginning of the in situ LCF test under synchrotron tomography [36] to characterize hard inclusions at a finer scale.

Grinding was performed on four sides and each edge of selected specimens using abrasive 
papers of grades up to 4000 grits in succession to obtain smooth surfaces and prevent the generation of stress concentration. A final polishing was performed using polishing cloths and diamond suspensions up to $1 \mu \mathrm{m}$ for surface observations.

\subsection{Testing procedure}

The tensile-tensile LCF tests, which are prescribed by the current available specimen clampings, were performed step by step with periodic interruptions with SR-CT in-situ observations performed during the hold stage of each step. The reader can refer to Ref. [36] for the detailed experimental protocol of the in-situ LCF tests performed on TOMCAT beamline at SLS (Fig. 2).

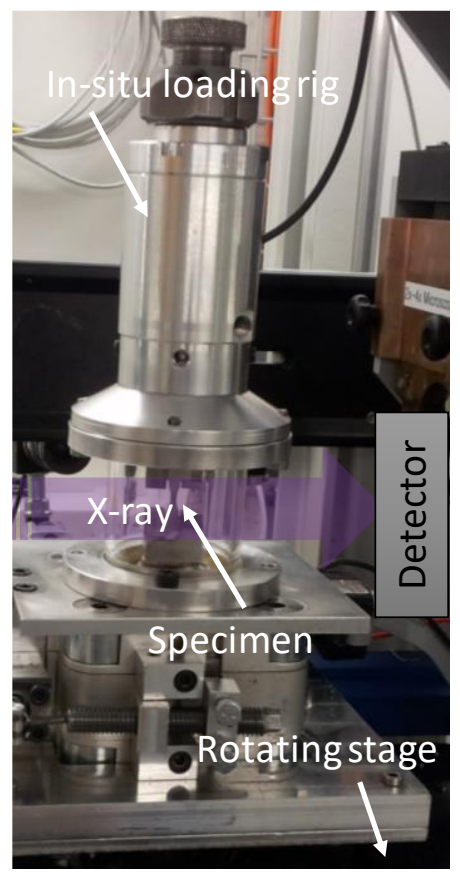

Fig. 2. Fatigue tests with SR-CT in-situ observations.

Finite Element (FE) simulation of the pores in the fatigue specimen was used to select Region Of Interest (ROI) where the in-situ observations were performed. The 3D mesh model representing the solid matrix, i.e. considering indifferently Al matrix, eutectic Si, iron intermetallics and copper containing phases all together, and the pores was obtained from the Lab-CT image [36]. A uniform displacement was imposed on the upper and lower surfaces of the FE model as boundary conditions. The average macroscopic deformation applied along the loading direction at the last iteration was set at about $1 \%$. The area where the largest strain localizations were observed was selected as the ROI.

Due to stress relaxation, cyclic softening and crack propagation, the load decreases during the tests. A significant decrease may occur for the maximum and the minimum load; the latter may fall close to $0 \mathrm{~N}$. In this case, the sample will no longer be held in the grips [37]. Therefore, the 
displacement was manually corrected during the test to maintain the overall stress at the initial set level [35]. The tests were performed on eight specimens of which two representative specimens, named as "Specimen 1 and 2", are described and analyzed in this paper. The basic loading conditions of each specimen are listed in Table 2 .

\begin{tabular}{|c|c|c|c|}
\hline \multicolumn{2}{|r|}{ Specimen } & 1 & 2 \\
\hline \multirow{3}{*}{$\begin{array}{l}\text { Loading } \\
\text { conditions }\end{array}$} & Max. stress (MPa) & 111 & 130 \\
\hline & R (Stress Ratio) & 0.1 & 0.1 \\
\hline & Average max. strain* & $0.26 \sim 0.28 \%$ & $0.11 \sim 0.17 \%$ \\
\hline \multirow{4}{*}{ Results } & Cracks initiation observed & \multicolumn{2}{|c|}{$1^{\text {st }}$ cycle (during initial tensile stage) } \\
\hline & Initiation site & Pore & Pore $+\mathrm{Si}$ \\
\hline & Propagation path & \multicolumn{2}{|c|}{ Hard inclusions ( $\mathrm{Si}$, iron intermetallics, copper containing phases) } \\
\hline & Final failure (cycles) & $<15$ & $\approx 10500$ \\
\hline
\end{tabular}

*This value is measured by DVC as it is cannot be measured by the in-situ test rig.

Table 2 Basic loading conditions and results of tests

\subsection{Post-mortem analysis}

A SR-CT scan was performed on one part of each broken fatigue specimen in order to identify the final fracture path in 3D.

The failed specimens were also examined using SEM to identify the hard inclusions involved in the crack and the damage mechanisms of hard inclusions. A chemical composition analysis was performed using EDS in three regions of each specimen, i.e. (1) the crack area; (2) the whole fracture surface; (3) an arbitrary region outside the fracture surface on the flat surface. The elements that were analyzed are: Al- the matrix of material; $\mathrm{Si}$ - associated to $\mathrm{Si}$ phase; $\mathrm{Fe} / \mathrm{Mn}$ - associated to iron intermetallics; $\mathrm{Cu}$ - associated to $\mathrm{Al}_{2} \mathrm{Cu}$ and $\mathrm{AlCuMgSi}$ phases; $\mathrm{Mg}$ - associated to $\mathrm{AlCuMgSi}$ phase.

The total acquisition time for one elemental map is about 2-3 hours using 30-50 images with a dwell time of 20-30 seconds for each image. Each elemental map is superimposed on the Back Scattered Electron (BSE) image in order to observe the relations between the microstructure of the fracture surface and the distribution of the constituents. Both fracture surfaces images of each specimen are analyzed as following. Symmetry, rotation and rigid registration using Image J plugins ("Extract SIFT Correspondences[38]" to find the rigid transformation between matching features on the two fracture surfaces and "bUnwarpJ[39]" to apply the transformation found on the X-ray map) were performed on one of the two images to allow comparison of the constituents in the same position on the two fracture surfaces. If the same constituents are identified in the same location on both fracture surfaces, the failure mechanism of hard particles is assumed to be fracture. Otherwise, 
it is supposed to be decohesion/debonding.

\subsection{Volumetric full-field measurement}

Volumetric full-field measurement was performed by using Digital Volume Correlation (DVC) method, which is an extension of the well-developed Digital Image Correlation (DIC) method. DVC method was developed from the end of 1990s [40], and is now widely used due to the expansion of 3D advanced imaging devices [41]. It directly provides volumetric displacements and strains full-fields by comparing the CT images of specimen volume in different deformed states. In this study, it was performed using YaDICs - Digital Image Correlation 2D/3D software [42], an in-house developed software. The presence of numerous and finely dispersed microstructural features, particularly $\mathrm{Si}$, is used as natural tracers for DVC. The reader is referred to Ref [35,43] for more details. Several types of measurements were performed:

1) DVC measurements were performed between the minimum load of $1^{\text {st }}$ cycle and the maximum loads of other cycles to obtain the cumulated displacement and strain fields in the bulk at different cycles and the average cumulated deformation along the loading direction at different cycles. Indeed, the latter was not monitored in real-time during the test as an extensometer would have obstructed the X-ray beam during the rotation of specimen (shown in Table 2). Only the applied instantaneous load was directly measured during the in-situ fatigue tests.

2) DVC measurements were performed between the minimum and the maximum loads of the same cycle in order to compute the intra-cycle displacement field along the loading direction and extract the field of Crack Opening Displacement (COD). COD was computed using two slices of the displacement field perpendicular to the loading direction: one above and one below the studied crack. The subtraction operation between these two slices gives access to a COD map. This method of COD calculation was used to study crack propagation in References [30,44].

3) DVC measurements performed at the minimum load between the $1^{\text {st }}$ cycle and the minimum load of other cycles allow obtaining the residual plastic deformation zones at different cycles [37].

Measurement uncertainty was used to assess the accuracy of DVC [45,46]. It is usually evaluated through the comparison between a prescribed displacement and the one measured from DVC [47,48]. The displacement may be a translation of a virtual image or a translation of the physical object [37]. The first case is used to test the algorithm and the texture of the image [49] and the second allows in 
addition to take into account all the image acquisition system for example reconstruction artifacts [31]. Therefore, the second method was used in this study. The uncertainty is estimated from the standard deviation of the displacement field measured by DVC between two images, i.e. one at a reference position and another one after a translation [49-51] $(10 \mu \mathrm{m}$ in the present case) of the specimen in a direction perpendicular to the beam direction and to the axis of rotation of the stage.

Fig. 3 shows the comparisons between the accuracies of DVC measurement (A319 SR-CT) in this study and that in the references [36] for A319 Lab-CT, [47] for A356 Lab-CT, [49] for polypropylene solid foam SR-CT, [44] for cast iron Lab-CT, and [30] for cast iron SR-CT. A spatial resolution of measurement close to the microstructural scale, i.e. with a cubic element having an edge length close the thickness of the different phases, is required in order to establish relations between microstructures and mechanical fields. At this high spatial resolution, the measurement accuracies should be such that: (1) element size is much larger than uncertainties (about thousand times), i.e. it is reliable to measure the deformations accurately in the order of percent and more; (2) the uncertainties are generally smaller than that in the literature in the case of the same element size. The measurement accuracy of DVC technique depends on the number and distribution of revealed natural tracers in digital images. The natural tracers for DVC measurements in A319 alloy are listed in Table 3. In DVC measurement using SR-CT, the Si phase, which occupies about half volume of hard inclusions, is revealed thanks to phase contrast and acts as a natural speckle for the measurement. Thus, 3D measurement using SR-CT has a higher accuracy than that using Lab-CT. In contrast, for cast iron, the spherical graphite nodules are the only natural markers for DVC either by using lab-CT or SR-CT, thus their measurement accuracies are virtually the same.

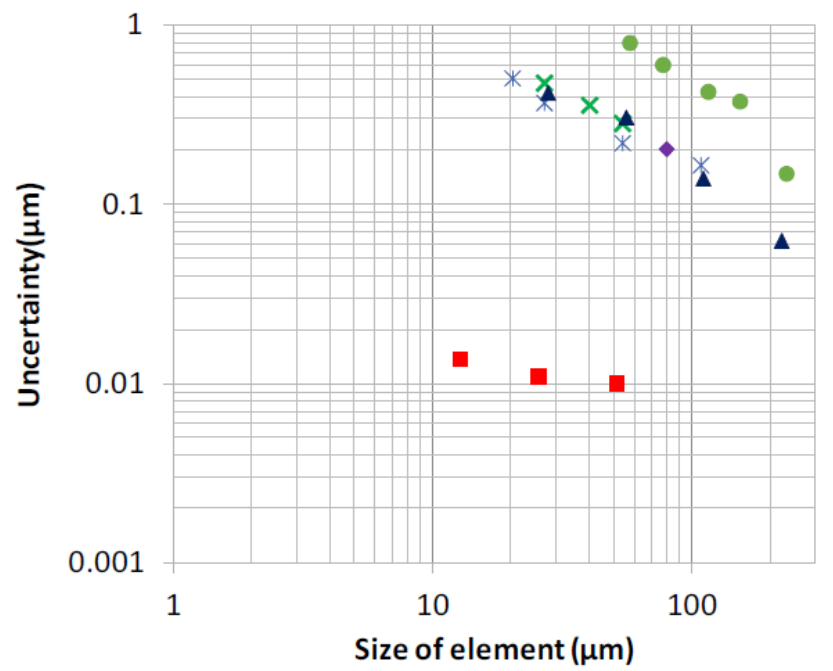

This Study:

- A319 SR-CT

References:

$*$ A319 Lab-CT ${ }^{[36]}$

$\times$ A356 Lab-CT ${ }^{[47]}$

- polypropylene foam SR-CT ${ }^{[49]}$

- cast iron SR-CT ${ }^{[43]}$

$\Delta$ cast iron lab-CT ${ }^{[30]}$

Fig. 3. Comparisons of measurements uncertainties as function of element size in this study and in the references [30, 36, 43, 47,49]. 


\begin{tabular}{cccc}
\hline \multirow{2}{*}{ Observation mode } & \multicolumn{3}{c}{ Natural tracers } \\
\cline { 2 - 4 } & Hard inclusions (except Si) & Si & Al matrix \\
\hline 3D (SR-CT) & Yes & Yes & No \\
3D (Lab-CT)[36] & Yes & No & No \\
\hline
\end{tabular}

Table 3 Natural tracers for DVC measurements on A319 alloy

Measurement uncertainty decreases with the increasing of element size, but as mentioned before a large element size will reduce the spatial resolution. For a compromise between the measurement accuracy and the spatial resolution, an element size of 8 voxels (about $13 \mu \mathrm{m}$ ) was used in this study. Therefore, the spatial resolution of DVC is close to the size of the thinnest microstructural constituents while the uncertainty, which was estimated for $U z$ (displacement along the tensile loading direction), remains low at 0.008 voxels (about $0.013 \mu \mathrm{m}$ ).

\section{Results}

The results of two representative specimens presented in this paper, i.e. "Specimen 1 and 2", are listed in Table 2. Specimen 1 fractured in less than 15 cycles while Specimen 2 fractured after 10500 cycles.

\subsection{SR-CT in-situ observations}

The pores in the useful length of Specimens 1 and 2 were characterized by Lab-CT and their rendering are shown in Fig. 4. The Feret diameter, which is defined as the maximum distance between two parallel planes restricting the object perpendicular to that direction, is used to characterize the size of pores in the studied material [35,36]. Pores A, B, C, D in Fig. 4b are the four largest pores in the selected ROI for the in-situ observations; their main parameters are given in Table 4. The largest pore in the selected ROI of Specimen 2 is shown in Fig. 4d. 

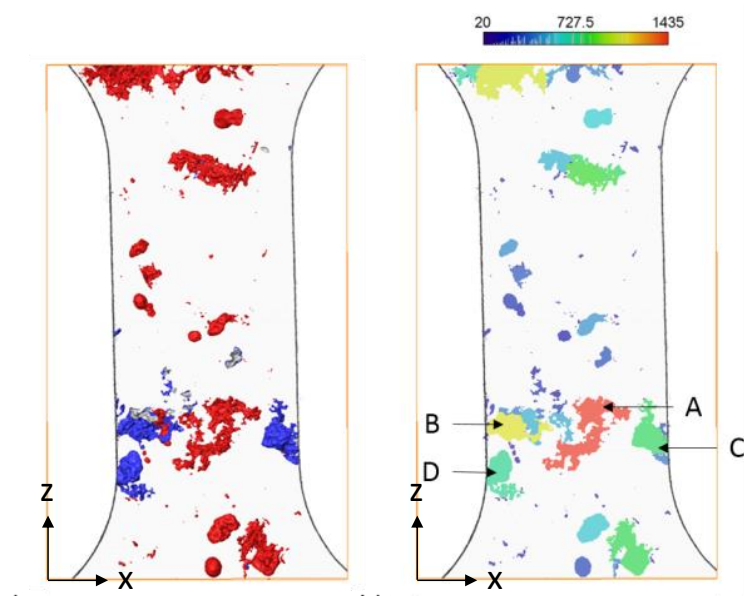

a)

b)

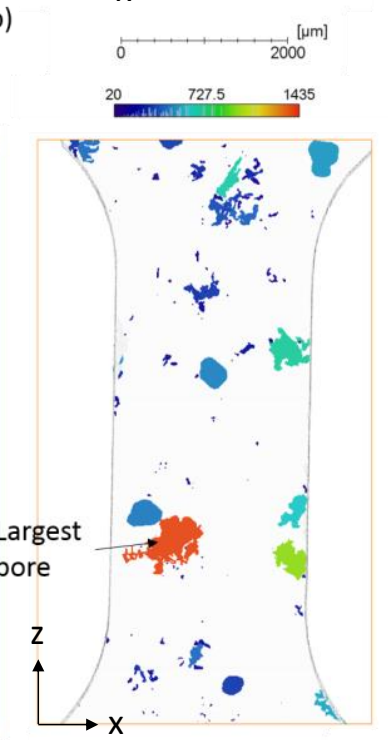

c)

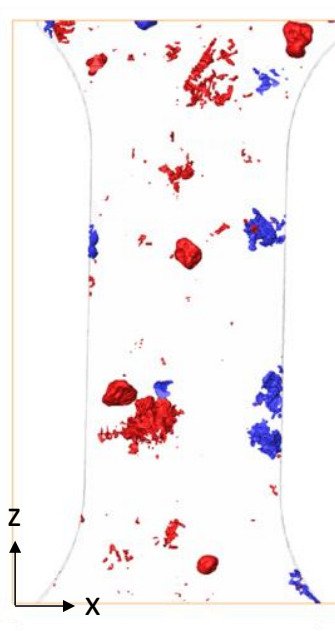

d) ${ }_{2000}^{[\mu m]}$

Fig. 4. 3D rendering of pores in the useful length of (a, b) Specimen 1 and (c, d) Specimen 2. The internal pores (subsurface pores) are shown in red and open pores (surface pores) are shown in blue in (a, c); the pores are colored by the Feret diameter (colorbar in $\mu \mathrm{m})$ in $(\mathrm{b}, \mathrm{d})$.

\begin{tabular}{|c|c|c|c|c|}
\hline Pore & Feret diameter $\mathbf{( m m})$ & Sphericity $(\mathbf{F})$ & Type & On fracture surface \\
\hline A & 1.55 & 0.09 & $\begin{array}{c}\text { Subsurface pore } \\
\text { Min. distance to surface: } 0.3 \mathrm{~mm}\end{array}$ & yes \\
\hline B & 0.81 & 0.19 & Surface pore & yes \\
\hline C & 0.76 & 0.28 & Surface pore & yes \\
\hline D & 0.71 & 0.33 & Surface pore & no \\
\hline others & $<0.51$ & - & - & - \\
\hline
\end{tabular}

Table 4 Parameters of large pores in Fig. $4 \mathrm{~b}$ and $5 \mathrm{~b}$.

Fig. 5 shows the slice by slice analysis of the SR tomographic images of Specimen 1 at different cycles as well as 3D rendering of pores, cracks and fracture surface. Fig. 5a reveals that cracks are located at hard inclusions around pores, including eutectic $\mathrm{Si}$, iron intermetallics (both $\alpha$ and $\beta$ 
phases) and copper containing phases. However, no crack propagation was observed from the $1^{\text {st }}$ cycle to the $10^{\text {th }}$ cycle, which was the last scan taken before failure. In Fig. 5b, Pores A, B, C and D are the four largest pores in the ROI of Specimen 1. Other pores are either far away from final fracture surface and small (Feret diameter less than $0.51 \mathrm{~mm}$ ) or close to the final fracture surface but much smaller, i.e. less than $0.39 \mathrm{~mm}$ which is one quarter of the size of the largest pore $(1.55 \mathrm{~mm})$. The majority of cracks nucleated around the second largest pore, i.e. Pore B, while only some small cracks nucleated around the largest pore, i.e. Pore A.

(a)

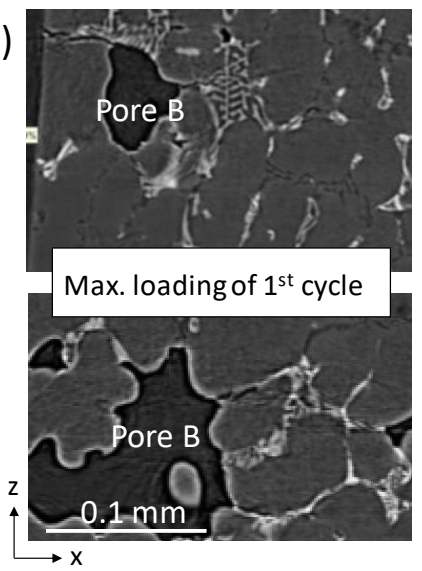

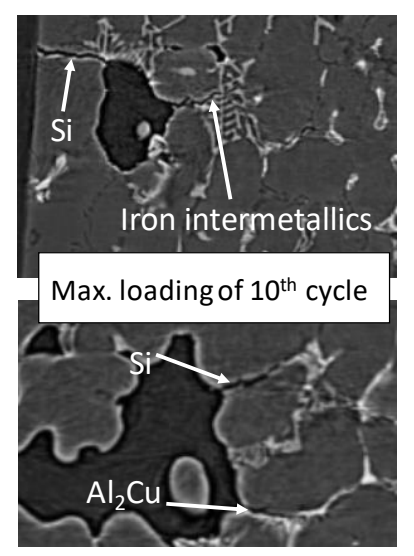

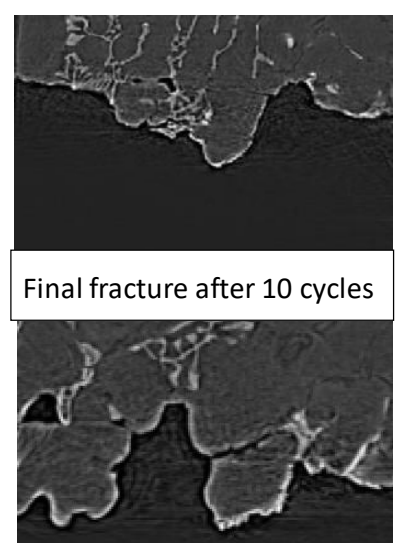

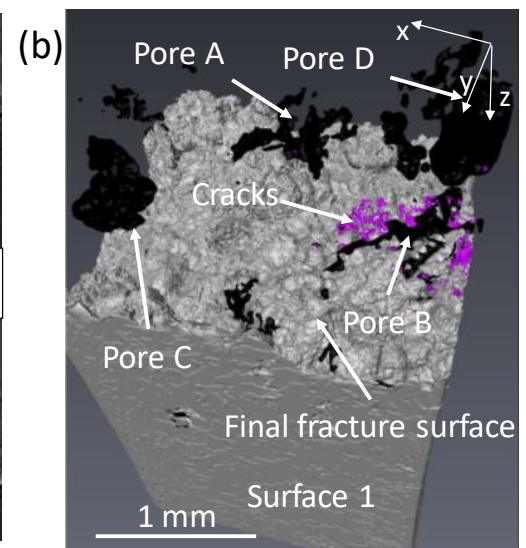

Fig. 5. Specimen 1: (a) two examples showing cracks in the same slice of SR-CT images at different stages (top: one slice about $1.1 \mathrm{~mm}$ below the flat surface; down: about $0.8 \mathrm{~mm}$ below the flat surface, i.e. Surface 1 in (b)); (b) $3 \mathrm{D}$ rendering of pores, cracks and final fracture surface.

Fig. 6a shows the SR-CT slices with the 3D rendering of pores and fracture surface in Specimen 2. It indicates that the final fracture of Specimen 2 was caused by two main cracks initiated at the $1^{\text {st }}$ cycle: Crack 1 initiated at a eutectic Si particle on the surface; Crack 2 initiated at a eutectic Si particle close to a large subsurface shrinkage pore that is the largest pore $($ Feret diameter $=1.22 \mathrm{~mm})$ in Specimen 2.

Fig. $6 \mathrm{~b}$ shows Cracks 1 and 2 of Specimen 2 in 3D at different cycles viewed along loading direction. Cracks were observed to propagate along eutectic $\mathrm{Si}$, iron intermetallics and copper containing phases. Crack 2 propagated around the largest pore, while Crack 1 propagated from surface towards this largest pore. When Crack 1 and Crack 2 coalesced after 10500 cycles, the final fracture occurred in a few cycles.

In addition, eutectic $\mathrm{Si}$ inclusions were observed more often than other hard inclusions both at crack initiation sites and crack propagation paths for both Specimen 1 and 2 in the SR-CT slices. 

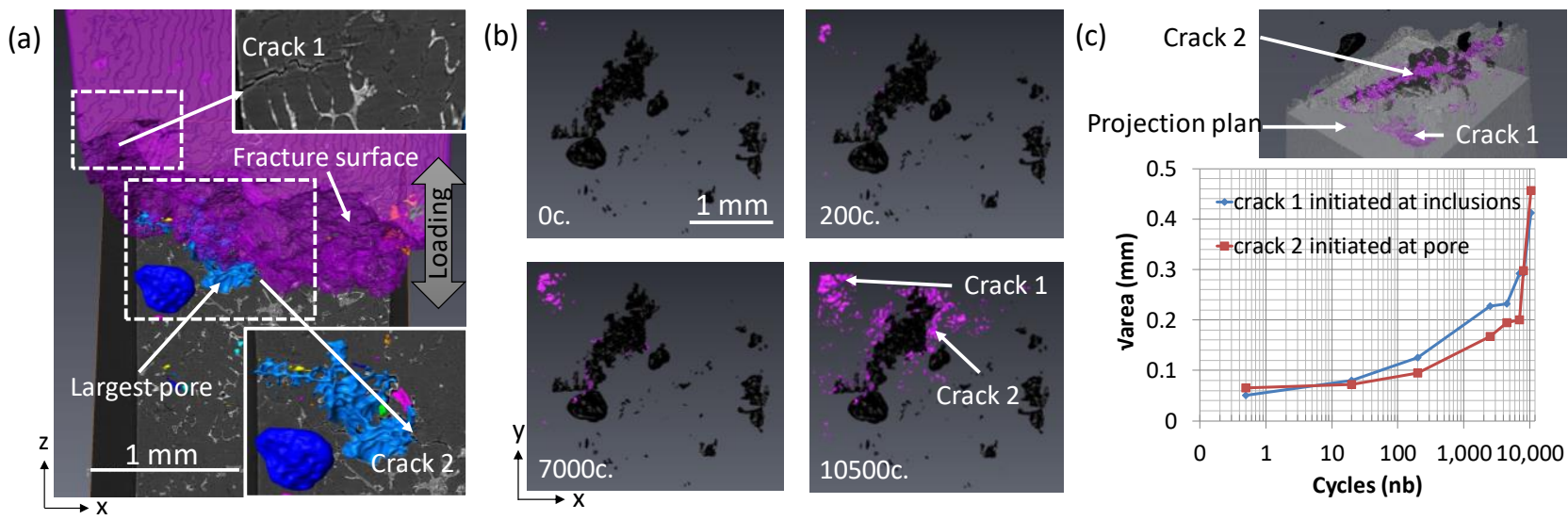

Fig. 6. Specimen 2: (a) Comparison of 3D rendering of pores and fracture surface and tomographic image slice revealed the two main cracks initiated around a large pore (Crack 2) and at hard inclusions at a corner of specimen (Crack 1); (b) 3D cracks around the 3D rendered pores at different cycles (view along the loading direction); (c) cracks length evolution with the number of cycles with the projection plane used for the cracks measurements (top).

\subsection{DVC measurements}

The cumulated displacement and strain fields at different cycles were analyzed slice by slice by comparing with cracks and microstructures in SR-CT images. The quantitative deformation values are reliable before the initiation of cracks while they correspond to the displacement discontinuity across the crack's faces once cracks have nucleated. Strain fields are obtained from the displacement fields through derivative operations so that a discontinuity will yield a high value of "strain". Consequently, local strains could only be analyzed at a given point before a crack nucleates at this point or reaches it by crack growth. Once cracks are nucleated, the displacement discontinuities could be used to quantify the cracks, as they allow measuring the Crack Opening Displacement (COD). One example for Specimen 2 is shown in Figs. 7 and 8. One slice of tomographic image, which is about $84 \mu \mathrm{m}$ below surface, is considered and shown with 3D rendering of pores and fracture surface in Fig. 7c. The displacement fields in Figs. 7a and b and strain fields in Figs. 8a-f show the fields of this slice at different cycles in translucent with the tomographic image slice in behind.

In the displacement field in Fig. 7, at 20 cycles in the slice shown in Fig. 8a, Crack 2 has not nucleated yet so that no displacement discontinuities could be identified; Crack 1 is still so short that its limited opening makes the displacement discontinuity hardly visible. However, with crack propagation and increasing of crack opening under cyclic loading, at 10500 cycles (Fig. 7b), these displacement discontinuities at crack path become quite visible. In addition, at 10500 cycles (Fig. 7b) even if no cracks are observed on the final fracture path between Crack 1 and Crack 2, a stronger displacement gradient is visible in this area. 

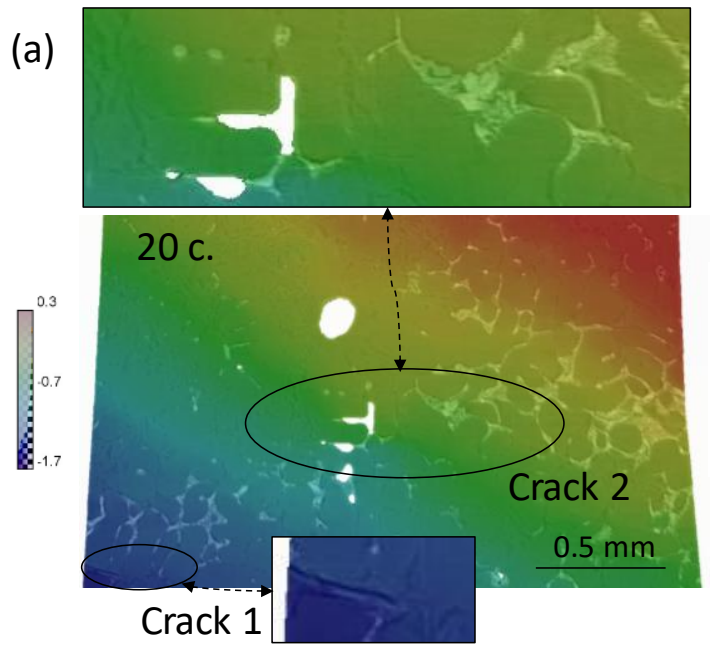

(b)
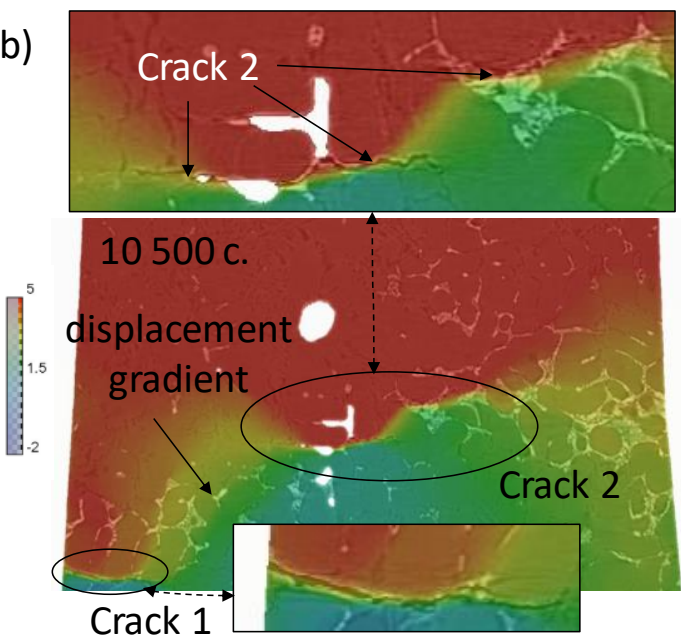

(c)

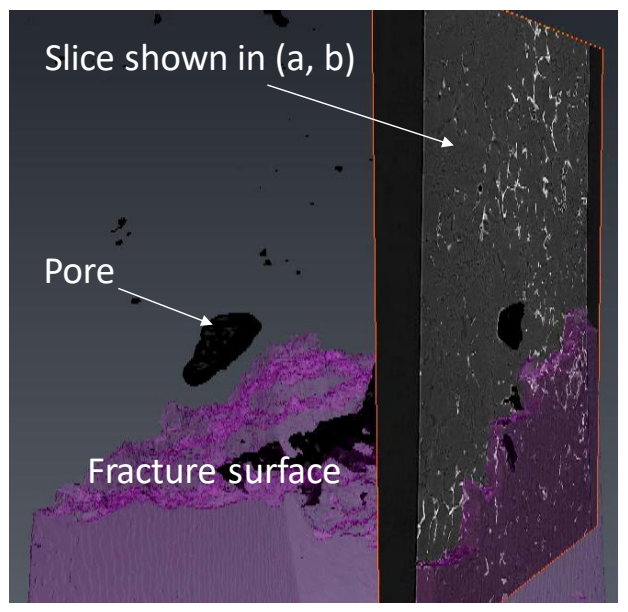

Fig. 7. Cumulated displacement field along the loading direction of Specimen 2 in one slice (about $84 \mu \mathrm{m}$ below the flat surface): DVC measurements were performed between the minimum load of $1^{\text {st }}$ cycle and the maximum loading of (a)20 cycles and (b) 10500 cycles; the selected tomographic slice is shown behind the translucent measured field in (a) and (b) and shown with a 3D rendering of pores and fracture surface in (c).

In order to quantify the displacement discontinuities, COD maps [30,44] are obtained from DVC performed between the minimum and maximum load of each cycles (Fig. 9). In Fig. 9, the outside areas are shown in black and the projections of pores located between the two selected slices are also shown in black in order to cover the deformation of pores. Unfortunately, some small cracks located in the vertical direction to the projection of pores are also covered. Even if crack propagation was not observed from the 1st cycle to the 10th cycle for Specimen 1, Fig. 9a shows the increasing of COD with cyclic loading. Fig. 9b shows that the COD of both Crack 1 and Crack 2 in Specimen 2, which were observed to propagate, increase with the cyclic loading. 
(a)

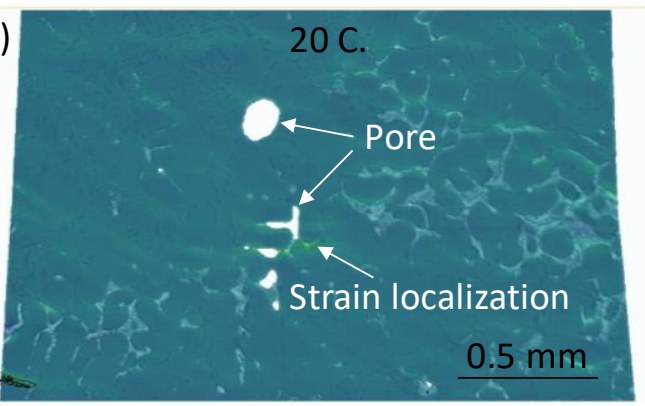

(c)

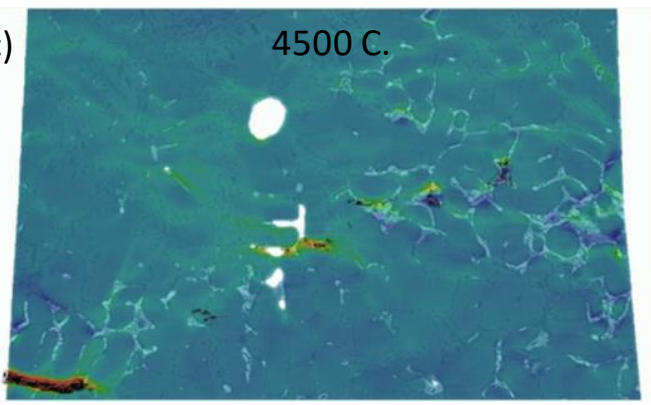

(e)

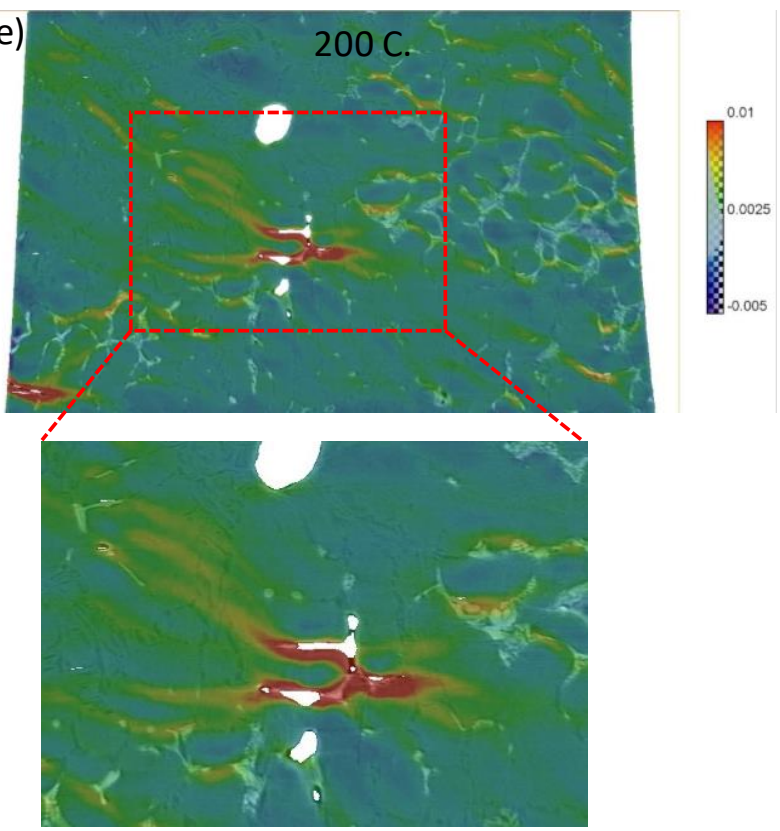

(b)

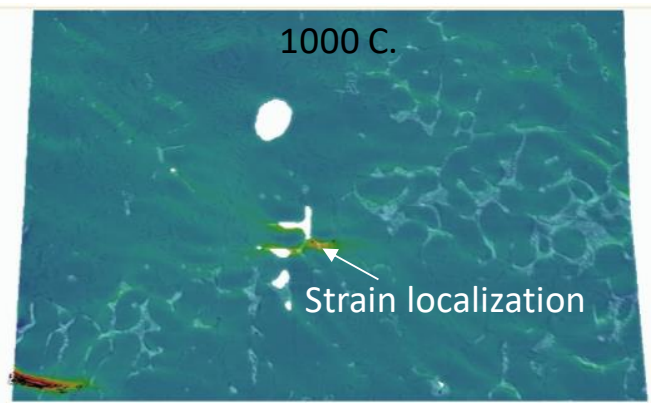

(d)
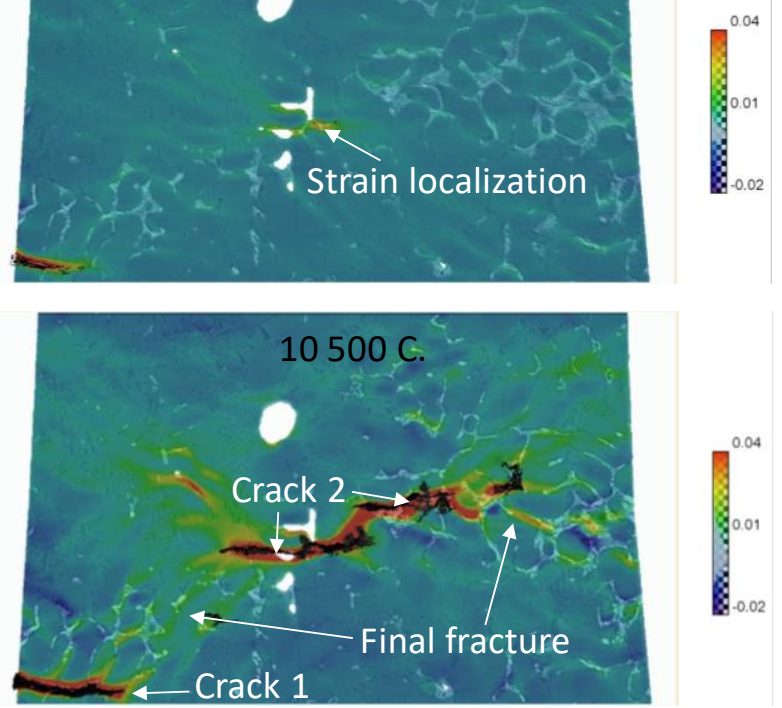

(f)

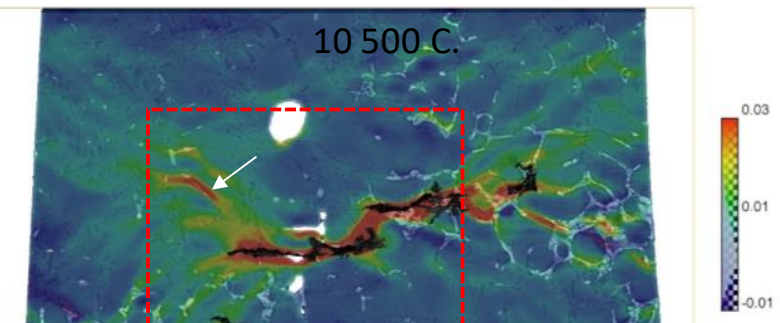

Fig. 8. Cumulated strain field along the loading direction of Specimen 2 in the same slice as Fig. 7: DVC measurements were performed between the minimum load of $1^{\text {st }}$ cycle and the maximum load of other cycles. The selected tomographic slice at the corresponding cycle is shown behind the translucent measured field; the 3D rendering of segmented cracks at the corresponding cycle is shown in black; (a)-(d) are shown with a constant range of color bar for the comparisons between different cycles while (e) and (f) are shown with decreased range of color bar in order to highlight the strain localizations.

The displacement fields allow only observing the relations between the displacement discontinuities and the existing cracks. The strain fields are then necessary to better analyze the heterogeneities and localizations such as the strongest displacement field gradient in Fig. 7b. In the strain field (Fig. 8), strain localizations were mainly observed at hard inclusions around or far away 
from pores, thus hard inclusions are responsible for strain localizations certainly due to local strain incompatibilities. The relations between strain localizations and crack nucleation and growth at hard inclusions could also be established. Slight strain localizations are observed both at Crack 1 and 2 at 20 cycles and are then observed to grow in size with crack propagations until the last step before final failure, i.e. 10500 cycles.

(a)
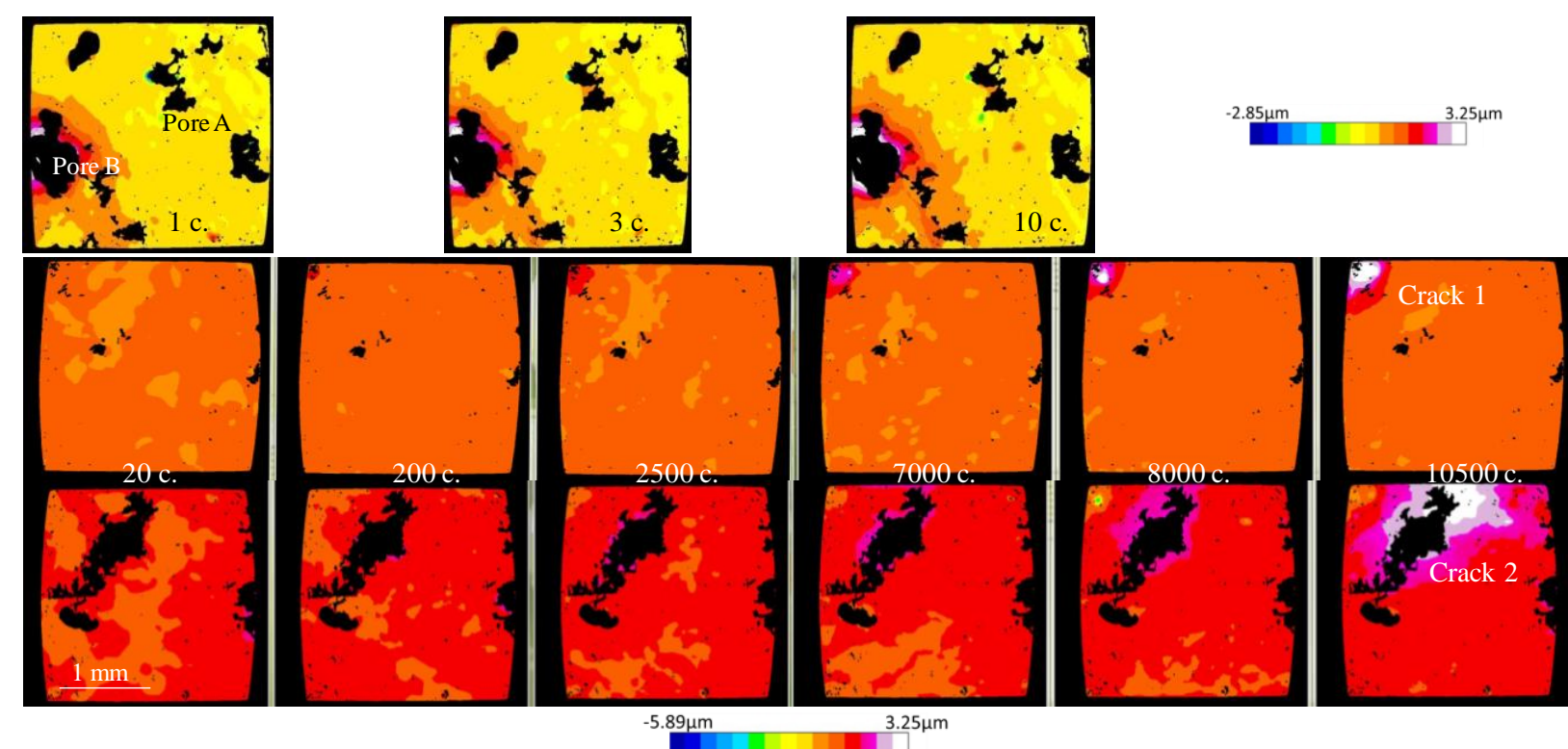

Fig. 9. Cracks opening displacement maps with number of cycles for (a) Specimen 1 and (b) Specimen 2 (top: crack 1, bottom: crack 2).

In Fig. 8a and b as well as in Fig. 8e, Crack 2 has apparently not nucleated at the current slice, however, strain localizations have already been observed. Once cracks nucleated in the current slice, i.e. Crack 1 in Figs.8a-f and Crack 2 in Figs. 8c, d and f, strain localizations were also observed ahead of the crack tip in areas where crack propagated in the following cycles. At 10500 cycles (Fig. 8d), strain localizations are observed on the final fracture path as indicated by arrows. Strain localizations were often found at hard inclusions sometimes out of the final fracture area (such as the area marked with an arrow in Fig. 8f) even if microcracks cannot always be identified (under the current resolution of SR-CT).

The cumulated residual strain field at minimum load (Fig. 10) are due to cumulated plastic deformation before crack nucleation or ahead of the crack tip. The red color localizations in Fig. 10b are produced by residual crack opening/discontinuity and should not be confused with deformation. Even if Crack 2 has not nucleated at 20 cycles, plastic deformation localizations have already been observed. Once crack nucleated, plastic deformation localizations ahead of crack tip were observed at areas that will correspond to the crack growth path in the following cycles. 


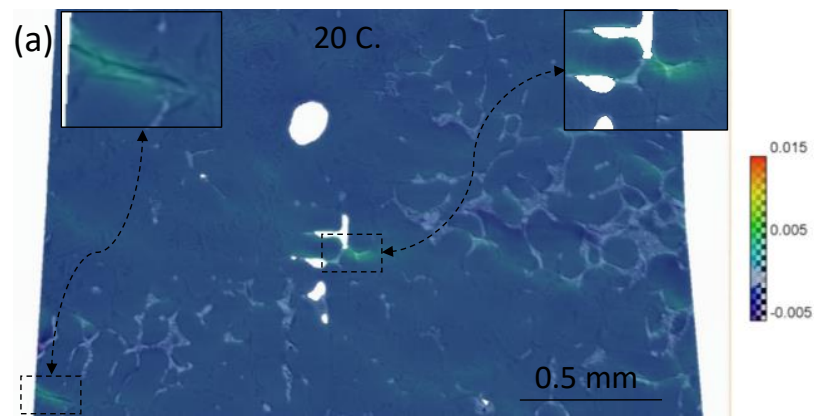

(b)

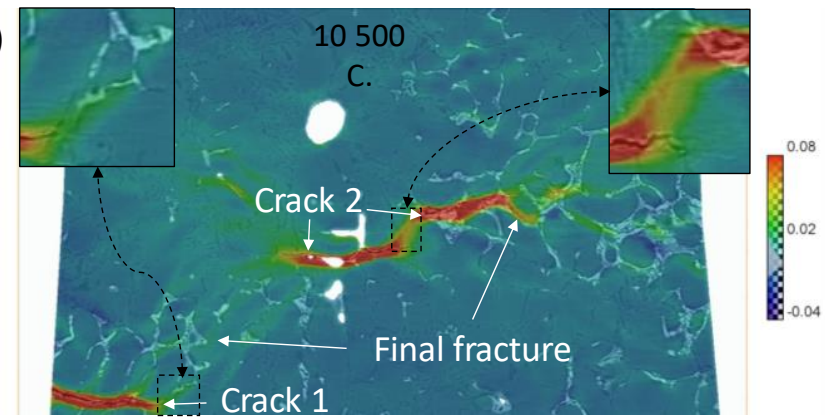

Fig. 10. Residual strain field along the loading direction of Specimen 2 in the same slice as Fig. 7: DVC measurements were performed between the minimum load and the maximum load of the same cycle. The selected tomographic slice at the corresponding cycle is shown behind the translucent measured field.

\subsection{Post-mortem analysis}

Comparison of chemical compositions of the fracture surfaces with that of the specimen (Table 5) shows that the content of $\mathrm{Mg}, \mathrm{Si}, \mathrm{Fe}$, and $\mathrm{Cu}$ is higher in the fracture surfaces. It implies that cracks and final fracture are more prone to occur at $\mathrm{Si}$ phase, iron intermetallics, $\mathrm{Al}_{2} \mathrm{Cu}$ and $\mathrm{AlCuMgSi}$ phases than in $\mathrm{Al}$ dendrites in agreement with previous observations. As the different areas on the fracture surface have similar chemical compositions, hard inclusions play the same important roles whether in crack initiation during tensile stage, crack propagation and final fast fracture.

\begin{tabular}{|c|c|c|c|c|}
\hline Elements & $\mathbf{M g}$ & $\mathbf{S i}$ & $\mathbf{F e}$ & $\mathbf{C u}$ \\
\hline Ratios $\left(\frac{\text { mass fraction on fracture surface }}{\text { mass fraction on flat surface }}\right)$ & $2 \sim 7$ & $2 \sim 3$ & $3 \sim 5$ & $2 \sim 7$ \\
\hline
\end{tabular}

Table 5 Ratios of elements mass fraction on fracture surface and on flat surface

The distinction between the fracture of hard inclusions and their decohesion in SR-CT images is often difficult due to the limited resolution and especially to the phase contrast. Thus, elemental map by EDS is more precise for this distinction although, as a post-mortem analysis, it does not allow to determine which mechanism occurs first, i.e. fracture then decohesion or the reverse. Fig. 11 shows the example of Si in Specimen 2. The areas in orange correspond to fracture and those in purple to decohesion; the outlines of the cracks 1 (on the left) and 2 (on the right) are superimposed. Fig. 12 shows the corresponding quantitative analysis of the failure mechanisms. In general, the surface fractions of decohesion and fracture are almost identical when considering the whole fracture surface. 
However, crack initiation at $\mathrm{Si}$ particles on the corner of the test specimen (Crack 1) is followed by the fracture of Si particles in several places but with a predominance of decohesion outside the initiation site. This coexistence of the fracture and the decohesion of Si particles is also found on the crack 2 initiated on an internal micro-shrinkage and on the final fracture area.

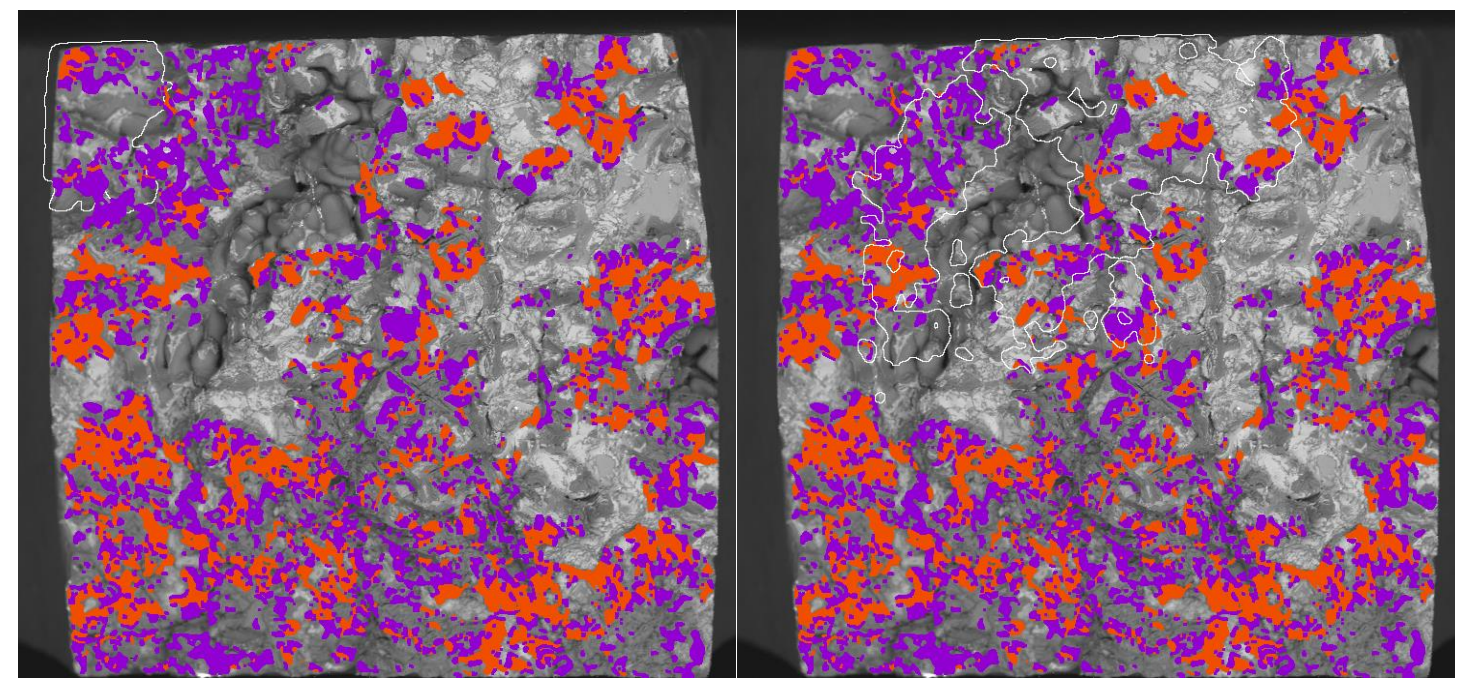

Fig. 11. Example showing the zone of fracture (in orange) and decohesion (in purple) of the eutectic Si identified on the EDS cartography with the outline of the crack 1 on the left and the outline of crack 2 on the right (Specimen 2)

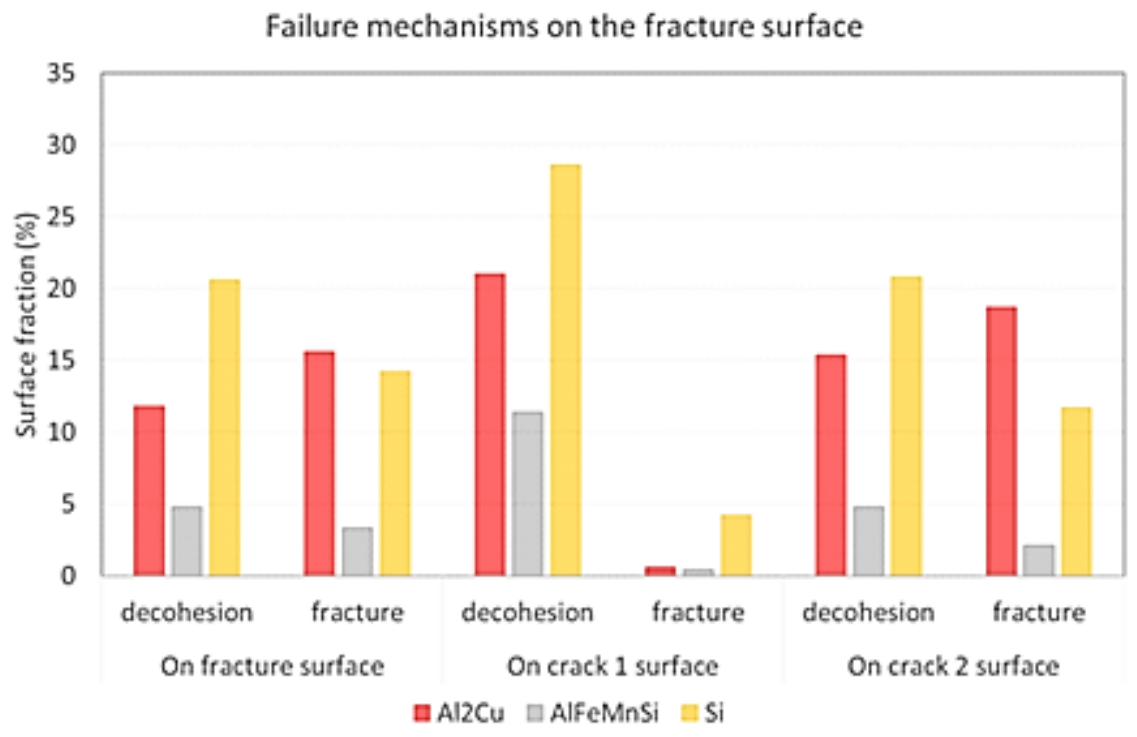

Fig. 12. Quantitative statistics of failure mechanisms on the fracture surface of Specimen 2

\section{Discussions}

SR-CT in-situ observations allow visualizing the process of crack initiation and propagation in the bulk. DVC estimates the mechanical fields and establishes the relations between cracks, 
mechanical fields and microstructures. The comprehensive analysis of damage mechanisms will be dealt with in this part based on the established relations.

\subsection{Crack initiation}

\subsubsection{Pores}

Cracks initiated around large pores for both specimens, thus pores are undoubtedly the most important microstructural feature for crack initiation in the studied material under LCF loading, as observed in HCF [6-12]. This is firstly due to the large size of pores in LFC alloy, which is much larger than the critical sizes, i.e. about $25 \mu \mathrm{m}$, reported in the literature for crack nucleation in high cycle fatigue [6,7]. In Specimen 1, cracks initiated at the two largest pores, i.e. Pore A (Feret diameter $=1.55 \mathrm{~mm})$ and $\mathrm{B}($ Feret diameter $=0.81 \mathrm{~mm})$. In Specimen 2, the shrinkage pore, around which Crack 2 initiated, is the largest pore where large strain localization occurred in FE simulation results for ROI selection. Its Feret diameter is about $1.22 \mathrm{~mm}$, while the size of other pores is smaller than $0.6 \mathrm{~mm}$. Its volume stands for almost $40 \%$ of the whole porosity in Specimen 2 . Cracks initiating from these large pores with the Feret diameter larger than $0.8 \mathrm{~mm}$ instead of from the numerous small pores proves that the size of pore is an important factor on crack initiations.

The importance of the location of pores is also highlighted. In Specimen 1, main cracks nucleated around surface Pore B, while only some small cracks nucleated around subsurface Pore A although it is the largest pore. Therefore a surface pore is more dangerous than a subsurface pore [8,9]. In Specimen 2, although the largest pore around which crack initiated is subsurface, its minimum distance to the surface is only about $0.02 \mathrm{~mm}$. Thus, it is not surprising that large cracks initiated around such a large shrinkage pore, which is very close to surface, in the absence of other large surface pores.

Shape of pores could have been considered important if the morphology of Pore B was sharper than Pore A in Specimen 1. The sphericity (F) value [36] in Table 4 shows that Pore A has actually a sharper morphology than Pore B. However, the value of Sphericity does not reflect the local shape of a pore, which may introduce a local stress concentration. In order to check the influence of the local shape of large pore on crack initiation, FE simulation was performed based on the porous model of Specimens 1 and 2 in monotonic tensile condition [20]. The porous model involves pores and solid matrix while hard inclusions are not taken into account. The material property was set as elastoplastic with an isotropic hardening, and the yield strength, Young modulus and strain hardening law for FE simulation were identified from macroscopic monotonic tensile tests on A319 LFC alloy 
with extensometer measurements. The average maximum strain listed in Table 2 was used as the macroscopic total deformation of FE simulations. One example in Fig. 13 shows that the strain localizations from FE simulations arise around a large pore at areas where cracks are observed in the tomographic image. Fig. 13 also shows that a locally strong curvature at the pore induces a locally high strain that favor crack nucleation.

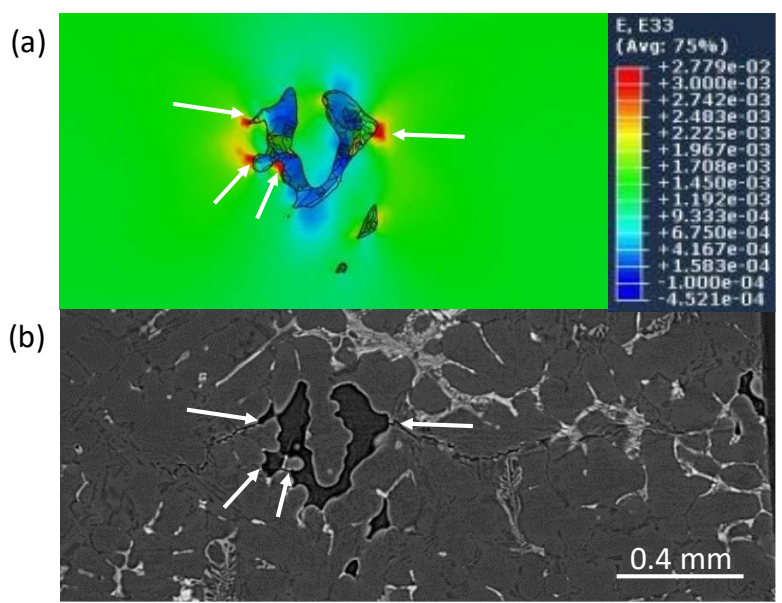

Fig. 13. Comparison of a same slice $(390 \mu \mathrm{m}$ below the flat surface) between (a) FEM simulation results of the strain field along the loading direction and (b) the tomographic image at 10500 cycle (Specimen 2).

The comparison between Specimen 1 and 2 also indicates the influence of the number of pores on crack initiation and fatigue life [11] : in the case of a lower overall applied loading, Specimen 1 has a much shorter life than Specimen 2 (Table 2); in addition, even if cracks nucleated at $1^{\text {st }}$ cycle for both specimens, COD measurements in Fig.12 show that COD at the crack mouth (CMOD) in Specimen 1 reached $3.25 \mu \mathrm{m}$ even at the $1^{\text {st }}$ cycle while COD in Specimen 2 was quite small at the $1^{\text {st }}$ cycle and did not reach $3.25 \mu \mathrm{m}$ until 8000 cycles when it has broken through the free surface. The above two mentioned abnormal phenomena could be ascribed to a larger volume fraction of pores in Specimen $1(0.79 \%)$ than in Specimen $2(0.42 \%)$.

\subsubsection{Hard inclusions}

In the FE simulation in Fig. 13, it should be noted that the strain localization areas around large pore include $\mathrm{Al}$ matrix and hard inclusions ( $\mathrm{Si}$ phase, iron intermetallics and copper containing phases). However, in SR-CT observation, cracks always initiate at the hard inclusions around large pores instead of at $\mathrm{Al}$ matrix. This emphasizes the role of hard inclusions on crack initiations: cracks nucleate at hard inclusions in areas where the strain is the highest due to the pore's geometry and orientation. The mechanical field measurement using DVC in section 3.2 (Crack 2 in Figs. 7 a and b) confirms that crack nucleated at hard inclusions in strain localizations areas. 
In literature, pores are often considered as the most probable crack initiation site. Pores, specimen's edge or even surface roughness generate a notch effect that provides a strain localization where crack can initiate as shown in Specimen 1 and 2. Even when large pores exist in a specimen, cracks were also observed to initiate at eutectic Si on the surface away from pores. In Specimen 2, Crack 1 was found to initiate from eutectic Si in the edge of flat surfaces close to the specimen's shoulder. Eutectic Si is reported [20] as potential crack nucleation site in the absence of defects above a critical size[6,7]. Even though there are large pores in Specimen 2, no pores whose size is larger than $0.02 \mathrm{~mm}$ are less than $0.5 \mathrm{~mm}$ far away from Crack 2 nucleation site. In addition, in Specimen 1, a large iron intermetallic was observed in the area around Pore B where cracks nucleated in the tensile stage of $1^{\text {st }}$ cycle (Fig. 5a). It is located in the plane perpendicular to the loading direction and thus is easy to fracture during the tensile loading. Hence, this may also be one possible reason why more cracks initiated around Pore B.

In summary, cracks are prone to initiate at hard inclusions in areas where there is a high enough stress concentration, which may be induced by large pores (majority case in the present study) or by specimen geometry such as the edge of the specimen.

In the strain localization area of a pore, the most probable reason why cracks initiate at hard inclusions instead of $\mathrm{Al}$ matrix is that a larger stress concentration is generated at hard inclusions than in $\mathrm{Al}$ matrix because hard inclusions have a higher elastic modulus and are more fragile than $\mathrm{Al}$ matrix [52,53]. Moreover, they have locally sharp morphologies. This assumption can be supported by theoretical analysis using continuum mechanics and FE simulations in literature $[19,54-56]$. In fact, strain localizations were indeed observed at hard inclusions in the experimental strain field from DVC measurements (Figs. 8 and 10) in this study and in a previous analysis [36].

In the present study, eutectic Si inclusions were observed more often than other hard inclusions at crack nucleation sites. Several reasons may be proposed:

(1) Volume fraction of eutectic Si is larger than that of other hard inclusions so that the probability of having a eutectic Si particle close to the corner of a critical pore is also larger.

(2) In unmodified alloy, the morphology of Si phase is coarse [57], and the thickness of eutectic $\mathrm{Si}$ is smaller than other hard inclusions according to 2D characterizations [35]. Thus, eutectic Si may be more likely to generate pronounced stress concentration.

(3) Because of the high Mn content in the studied material, the content of $\beta$ iron intermetallic, which is more brittle, is reduced and the morphology of $\alpha$ iron intermetallic is refined [58,59].

However, more specimens should be tested using SR-CT in-situ tests in order to confirm the above assumption. 
As expected from the literature, no crack initiation was observed at slip bands. Actually, crack initiations in a cast HIP (Hot Isostatic Pressing) A319 alloy are observed at slip bands for thin SDAS (Secondary Dendrite Arm Space) and at rigid particles for coarse SDAS [60] . Crack nucleation at slip bands is generally reported in Al-Si alloys without pores under HCF [13,60]. When defects above a critical size or large defect-like particles are present, such as in the LFC A319 alloy of the present study, cracks will initiate at these defects rather than at slip bands in the $\mathrm{Al}$ matrix.

\subsection{Crack propagation}

Once cracks nucleated at hard inclusions in highly strained areas, they propagated along hard inclusions. However, more eutectic Si than iron intermetallics or copper containing phases was observed in crack path (Fig. 12). It could be explained by the three possible reasons previously discussed for the assumption that eutectic $\mathrm{Si}$ is more prone to crack nucleation than other hard inclusions plus an additional fourth reason. Indeed, eutectic Si is an interconnected phase that may extend to the whole volume while copper containing phases form less extended networks [35], thus the former provides a more continuous path for crack propagation than the later.

Crack propagations along hard inclusions can be ascribed to strain localizations ahead of crack tip at hard inclusions (e.g. in Figs. 8 and 10). Strain localizations were indeed observed in areas where crack propagations were observed in following cycles. The comparisons between DVC and FE in [36] confirms that the measured strain localizations could not be ascribed to the sole pores.

In order to study the propagation of the two cracks in Specimen 2 quantitatively, each crack segmented manually from SR-CT images [36] was projected on a plane perpendicular to the loading direction as shown in the top of Fig. 6c. The measured cracks lengths, i.e. the root square of the projection area, in Fig. 6c show that the propagation rate of Crack 1 is a little bit higher than that of Crack 2 before 8000 cycles. This may be due to a higher stress level at the surface corner than inside the specimen and a larger COD of Crack 1 than Crack 2 before 8000 cycles in COD map as shown in Fig. 9b.

\subsection{Damage mechanisms at hard inclusions}

The fractions of decohesion and fracture are almost identical in the fracture surface (Fig.12), except for the predominance of decohesion over fracture for Crack1. In the literature [61-63], particles in Al-Si alloys are reported to fail via a debonding mechanism at low applied strains and by both fracturing and debonding at high strains. However, the mechanisms may also depend on the type of particle, i.e. its size, shape and orientation, as well as the loading conditions and the strength 
of the Al matrix-particle interface. High strains were induced in the present study in the regime of LCF, thus both fracturing and debonding are observed in general. Local variation in size, shape and orientation of hard inclusions should be responsible as Crack 1 initiated first by breaking a ligament of a eutectic Si particle that forms a coral-like interconnected network and then it propagated by decohesion of this same network.

\subsection{Scenario of damage evolutions}

From the above analysis, cracks initiate at hard inclusions and propagate along hard inclusions due to strain localizations that eventually lead to inclusions failure. Understanding why such an event occurred is important to understand the damage mechanisms.

The fracture strength of individual Si particles in Al-Si alloys has already been studied in the literature [64-66] by using experimental and simulation methods. The stress at which Si particle fracture occurs is much higher than the ultimate strength of alloy, but the stress concentration sites induced by the presence of defects lower substantially particle strength. The fracture of Si particles also depends on their sizes, shape, orientations, and their connections with the neighbor particles.

Crack nucleates during tensile stage of $1^{\text {st }}$ cycle in the present study. In LCF, the loading applied to the specimen is high. In addition, in LFC alloy, large porosity volume fraction could increase the actual stress level and large pore or specimen edge induce high strain localization. Due to the coupling influences of the above two cases, the high local plastic strain level during tensile stage of $1^{\text {st }}$ cycle results in the failure of hard inclusions.

For crack necleation at hard inclusions, the local cumulated plastic strain increases with cyclic loading before crack initiation (e.g. Crack 2 in Fig. 8). Hard inclusions failed and cracks nucleated once the local cumulated plastic strain was high enough.

Once a crack has initiated, a strain localization area is induced around the crack tip. If the local strain level due to the coupling influence of crack tip and microstructure, i.e. pores and hard inclusions, arrives to a high enough level in one cycle, the hard inclusions at crack tip fail and thus result in crack propagation.

In Specimen 1, even if cracks did not propagate before 10 cycles, COD increases with cyclic loading so that the strain level at crack tip increases concomitantly. Thus, once the local strain localization at crack tip is high enough, hard inclusions failed suddenly after 10 cycles.

Hard inclusions form highly interconnected networks in the volume of alloy. These networks guarantee the continuous failure events of hard inclusions once crack has nucleated. Thus, crack propagates along hard inclusions. 


\section{Conclusions}

In order to study the damage micromechanisms of LFC A319 alloy in LCF, SR-CT in-situ observations and DVC measurements were employed. The damage process in the bulk of material was visualized in 3D and the relations between crack initiation and propagation, mechanical fields and microstructures was established. The main conclusions are the followings:

- The relations between cracks and final fracture, and displacement discontinuities / strain localizations in the measured fields from DVC are indeed observed. These relations provide evidences to explain the damage mechanisms.

- Due to pore-induced stress concentration, most cracks nucleated at hard inclusions around large pores. Size, location, number and shape of pores have influence on crack initiation. Hence, the control of pores should be paid much attention in the following LFC process.

- Cracks initiate at hard inclusions and propagate along those inclusions due to strain localizations. Thus the damage process, i.e. crack initiation and propagation, can be considered as a series of failure events of hard inclusions under strain localizations.

- The interconnected hard inclusion networks guarantee the continuous failure events of hard inclusions and thus provide crack propagation paths. More eutectic Si than iron intermetallics or copper containing phases were observed to act as crack nucleation site or crack propagation path.

\section{Acknowledgements}

This research work was funded by INDiANA-ANR project (grant ANR-12-RMNP-0011) and PSA Peugeot Citroën. The authors would like to thank TOMCAT beamline at Swiss Light Source (SLS) for providing SR-CT beamtime, and the China Scholarship Council (CSC) for funding the PhD thesis of Long WANG.

\section{References}

[1] S. Tabibian, E. Charkaluk, A. Constantinescu, F. Szmytka, A. Oudin, TMF-LCF life assessment of a Lost Foam Casting A319 aluminum alloy, Int. J. Fatigue. 53 (2013) 75-81. https://doi.org/10.1016/j.ijfatigue.2012.01.012.

[2] M.B. Grieb, H.-J. Christ, B. Plege, Thermomechanical fatigue of cast aluminium alloys for cylinder head applications-experimental characterization and life prediction, Procedia Eng. 2 (2010) 1767-1776. https://doi.org/10.1016/j.proeng.2010.03.190.

[3] N.T. Niane, J.-P. Michalet, Validation of Foundry Process for Aluminum Parts with FLOW-3D $\begin{array}{lllll}\text { Software, in: } & \text { Flow } & \text { Sci., } & \text { New } & \text { York, }\end{array}$ https://www.flow3d.com/wp-content/uploads/2014/08/Validation-of-Foundry-Process-for-Aluminu 
m-Parts-with-FLOW-3D-Software.pdf (accessed August 9, 2016).

[4] P.-M. Geffroy, M. Lakehal, J. Goñi, E. Beaugnon, J.-M. Heintz, J.-F. Silvain, Thermal and mechanical behavior of Al-Si alloy cast using magnetic molding and lost foam processes, Metall. Mater. Trans. A. 37 (2006) 441-447. https://doi.org/10.1007/s11661-006-0015-0.

[5] S. Tabibian, Contributions to Thermomechanical Fatigue Criteria for Lost Foam Casting Aluminum Alloys, Ecole Centrale de Lille, 2011.

[6] Q.G. Wang, D. Apelian, D.A. Lados, Fatigue behavior of A356-T6 aluminum cast alloys. Part I. Effect of casting defects, J. Light Met. 1 (2001) 73-84. https://doi.org/10.1016/S1471-5317(00)00008-0.

[7] H. Zhang, H. Toda, H. Hara, M. Kobayashi, T. Kobayashi, D. Sugiyama, N. Kuroda, K. Uesugi, Three-Dimensional Visualization of the Interaction between Fatigue Crack and Micropores in an Aluminum Alloy Using Synchrotron X-Ray Microtomography, Metall. Mater. Trans. A. 38 (2007) 1774-1785. https://doi.org/10.1007/s11661-007-9214-6.

[8] Y.X. Gao, J.Z. Yi, P.D. Lee, T.C. Lindley, A micro-cell model of the effect of microstructure and defects on fatigue resistance in cast aluminum alloys, Acta Mater. 52 (2004) 5435-5449. https://doi.org/10.1016/j.actamat.2004.07.035.

[9] H.R. Ammar, A.M. Samuel, F.H. Samuel, Porosity and the fatigue behavior of hypoeutectic and hypereutectic aluminum-silicon casting alloys, Int. J. Fatigue. 30 (2008) 1024-1035. https://doi.org/10.1016/j.ijfatigue.2007.08.012.

[10]J.Z. Yi, Y.X. Gao, P.D. Lee, H.M. Flower, T.C. Lindley, Scatter in fatigue life due to effects of porosity in cast A356-T6 aluminum-silicon alloys, Metall. Mater. Trans. A. 34 (2003) 1879-1890. https://doi.org/10.1007/s11661-003-0153-6.

[11]J.-Y. Buffière, S. Savelli, P.H. Jouneau, E. Maire, R. Fougères, Experimental study of porosity and its relation to fatigue mechanisms of model $\mathrm{Al}-\mathrm{Si} 7-\mathrm{Mg} 0.3$ cast $\mathrm{Al}$ alloys, Mater. Sci. Eng. A. 316 (2001) 115-126. https://doi.org/10.1016/S0921-5093(01)01225-4.

[12]K. Gall, M.F. Horstemeyer, B.W. Degner, D.L. McDowell, J. Fan, On the driving force for fatigue crack formation from inclusions and voids in a cast A356 aluminum alloy, Int. J. Fract. 108 (2001) 207-233. https://doi.org/10.1023/A:1011033304600.

[13]Q.G. Wang, D. Apelian, D.A. Lados, Fatigue behavior of A356/357 aluminum cast alloys. Part II - Effect of microstructural constituents, J. Light Met. 1 (2001) 85-97. https://doi.org/10.1016/S1471-5317(00)00009-2.

[14]V. Firouzdor, M. Rajabi, E. Nejati, F. Khomamizadeh, Effect of microstructural constituents on the thermal fatigue life of A319 aluminum alloy, Mater. Sci. Eng. A. 454-455 (2007) 528-535. https://doi.org/10.1016/j.msea.2007.01.018.

[15]A.J. Moffat, Micromechanistic analysis of fatigue in aluminium silicon casting alloys, phd, University of Southampton, 2007. http://eprints.soton.ac.uk/52400/ (accessed August 9, 2016).

[16]J.Z. Yi, Y.X. Gao, P.D. Lee, T.C. Lindley, Effect of Fe-content on fatigue crack initiation and propagation in a cast aluminum-silicon alloy (A356-T6), Mater. Sci. Eng. A. 386 (2004) 396-407. https://doi.org/10.1016/j.msea.2004.07.044.

[17]Z. Ma, A.M. Samuel, H.W. Doty, S. Valtierra, F.H. Samuel, Effect of Fe content on the fracture behaviour of $\mathrm{Al}-\mathrm{Si}-\mathrm{Cu}$ cast alloys, Mater. Des. 57 (2014) 366-373. https://doi.org/10.1016/j.matdes.2014.01.037.

[18]K.S. Chan, P. Jones, Q. Wang, Fatigue crack growth and fracture paths in sand cast B319 and A356 aluminum alloys, Mater. Sci. Eng. A. $341 \quad$ (2003) 18-34. 
https://doi.org/10.1016/S0921-5093(02)00196-X.

[19]D.L. McDowell, K. Gall, M.F. Horstemeyer, J. Fan, Microstructure-based fatigue modeling of $\begin{array}{lllllll}\text { cast A356-T6 alloy, } & \text { Eng. } & \text { Fract. } & \text { Mech. } & 70 & \text { (2003) }\end{array}$ https://doi.org/10.1016/S0013-7944(02)00021-8.

[20]J. Stolarz, O. Madelaine-Dupuich, T. Magnin, Microstructural factors of low cycle fatigue damage in two phase Al-Si alloys, Mater. Sci. Eng. A. 299 (2001) 275-286. https://doi.org/10.1016/S0921-5093(00)01428-3.

[21]P. Huter, P. Renhart, S. Oberfrank, M. Schwab, F. Grün, B. Stauder, High- and low-cycle fatigue influence of silicon, copper, strontium and iron on hypo-eutectic $\mathrm{Al}-\mathrm{Si}-\mathrm{Cu}$ and $\mathrm{Al}-\mathrm{Si}-\mathrm{Mg}$ cast alloys used in cylinder heads, Int. J. Fatigue. 82 (2016) 588-601. https://doi.org/10.1016/j.ijfatigue.2015.09.015.

[22]L. Ceschini, I. Boromei, A. Morri, S. Seifeddine, I.L. Svensson, Microstructure, tensile and fatigue properties of the $\mathrm{Al}-10 \% \mathrm{Si}-2 \% \mathrm{Cu}$ alloy with different $\mathrm{Fe}$ and $\mathrm{Mn}$ content cast under controlled conditions, J. Mater. Process. Technol. 209 (2009) 5669-5679. https://doi.org/10.1016/j.jmatprotec.2009.05.030.

[23]D. Ovono Ovono, I. Guillot, D. Massinon, Study on low-cycle fatigue behaviours of the aluminium cast alloys, J. Alloys Compd. 452 (2008) 425-431. https://doi.org/10.1016/j.jallcom.2006.11.052.

[24]T. Beck, D. Löhe, J. Luft, I. Henne, Damage mechanisms of cast Al-Si-Mg alloys under superimposed thermal-mechanical fatigue and high-cycle fatigue loading, Mater. Sci. Eng. A. 468-470 (2007) 184-192. https://doi.org/10.1016/j.msea.2006.05.177.

[25]T. Beck, I. Henne, D. Löhe, Lifetime of cast AlSi6Cu4 under superimposed thermal-mechanical fatigue and high-cycle fatigue loading, Mater. Sci. Eng. A. 483-484 (2008) 382-386. https://doi.org/10.1016/j.msea.2006.09.139.

[26]L. Salvo, P. Cloetens, E. Maire, S. Zabler, J.J. Blandin, J.Y. Buffière, W. Ludwig, E. Boller, D. Bellet, C. Josserond, X-ray micro-tomography an attractive characterisation technique in materials science, Nucl. Instrum. Methods Phys. Res. Sect. B Beam Interact. Mater. At. 200 (2003) 273-286. https://doi.org/10.1016/S0168-583X(02)01689-0.

[27]Y. Zhao, Z. Wang, C. Zhang, W. Zhang, Synchrotron X-ray tomography investigation of 3D morphologies of intermetallic phases and pores and their effect on the mechanical properties of cast Al-Cu alloys, J. Alloys Compd. $777 \quad$ (2019) 1054-1065. https://doi.org/10.1016/j.jallcom.2018.10.334.

[28]F. Chen, F. Mao, Z. Chen, J. Han, G. Yan, T. Wang, Z. Cao, Application of synchrotron radiation X-ray computed tomography to investigate the agglomerating behavior of TiB2 particles in aluminum, J. Alloys Compd. 622 (2015) 831-836. https://doi.org/10.1016/j.jallcom.2014.10.190.

[29]J.-Y. Buffiere, E. Maire, J. Adrien, J.-P. Masse, E. Boller, In Situ Experiments with X ray Tomography: an Attractive Tool for Experimental Mechanics, Exp. Mech. 50 (2010) 289-305. https://doi.org/10.1007/s11340-010-9333-7.

[30]N. Limodin, J. Réthoré, J.-Y. Buffière, F. Hild, S. Roux, W. Ludwig, J. Rannou, A. Gravouil, Influence of closure on the 3D propagation of fatigue cracks in a nodular cast iron investigated by X-ray tomography and 3D volume correlation, Acta Mater. 58 (2010) 2957-2967. https://doi.org/10.1016/j.actamat.2010.01.024.

[31]N. Limodin, J. Réthoré, J. Adrien, J.-Y. Buffière, F. Hild, S. Roux, Analysis and Artifact Correction for Volume Correlation Measurements Using Tomographic Images from a Laboratory 
X-ray Source, Exp. Mech. 51 (2010) 959-970. https://doi.org/10.1007/s11340-010-9397-4.

[32]H.A. Bale, A. Haboub, A.A. MacDowell, J.R. Nasiatka, D.Y. Parkinson, B.N. Cox, D.B. Marshall, R.O. Ritchie, Real-time quantitative imaging of failure events in materials under load at temperatures above $1,600{ }^{\circ} \mathrm{C}$, Nat. Mater. 12 (2013) 40-46. https://doi.org/10.1038/nmat3497.

[33]S. Dezecot, V. Maurel, J.-Y. Buffiere, F. Szmytka, A. Koster, 3D characterization and modeling of low cycle fatigue damage mechanisms at high temperature in a cast aluminum alloy, Acta Mater. 123 (2017) 24-34. https://doi.org/10.1016/j.actamat.2016.10.028.

[34]V. Mazars, O. Caty, G. Couégnat, A. Bouterf, S. Roux, S. Denneulin, J. Pailhès, G.L. Vignoles, Damage investigation and modeling of 3D woven ceramic matrix composites from X-ray tomography in-situ tensile tests, Acta Mater. $140 \quad$ (2017) 130-139. https://doi.org/10.1016/j.actamat.2017.08.034.

[35]L. Wang, Influence of the casting microstructure on damage mechanisms in Al-Si alloys by using 2D and 3D in-situ analysis, Ecole Centrale de Lille, 2015. http://www.theses.fr/2015ECLI0004 (accessed July 26, 2016).

[36]L. Wang, N. Limodin, A. El Bartali, J.-F. Witz, R. Seghir, J.-Y. Buffiere, E. Charkaluk, Influence of pores on crack initiation in monotonic tensile and cyclic loadings in lost foam casting A319 alloy by using 3D in-situ analysis, Mater. Sci. Eng. A. 673 (2016) 362-372. https://doi.org/10.1016/j.msea.2016.07.036.

[37]J. Lachambre, Développement d'une méthode de caractérisation 3D des fissures de fatigue à l'aide de la corrélation d'images numériques obtenues par tomographie X, Lyon, INSA, 2014. http://www.theses.fr/2014ISAL0050 (accessed August 28, 2016).

[38]Feature Extraction, ImageJ. (n.d.). https://imagej.net/Feature_Extraction (accessed April 11, 2020).

[39]BUnwarpJ - ImageJ, (n.d.). https://imagej.net/BUnwarpJ (accessed April 11, 2020).

[40]B.K. Bay, T.S. Smith, D.P. Fyhrie, M. Saad, Digital volume correlation: Three-dimensional strain mapping using X-ray tomography, Exp. Mech. 39 (1999) 217-226.

[41]B. Pan, D. Wu, Z. Wang, Internal displacement and strain measurement using digital volume correlation: a least-squares framework, Meas. Sci. Technol. 23 (2012) 045002. https://doi.org/10.1088/0957-0233/23/4/045002.

[42]R. Seghir, J.-F. Witz, YaDICs - Digital Image Correlation 2/3D software, (2014). http://www.yadics.univ-lille1.fr.

[43]S. Dezecot, J.-Y. Buffiere, A. Koster, V. Maurel, F. Szmytka, E. Charkaluk, N. Dahdah, A. El Bartali, N. Limodin, J.-F. Witz, In situ 3D characterization of high temperature fatigue damage mechanisms in a cast aluminum alloy using synchrotron X-ray tomography, Scr. Mater. 113 (2016) 254-258. https://doi.org/10.1016/j.scriptamat.2015.11.017.

[44]N. Limodin, J. Réthoré, J.-Y. Buffière, A. Gravouil, F. Hild, S. Roux, Crack closure and stress intensity factor measurements in nodular graphite cast iron using three-dimensional correlation of laboratory X-ray microtomography images, Acta Mater. 57 (2009) 4090-4101. https://doi.org/10.1016/j.actamat.2009.05.005.

[45]S.G. Rabinovich, Measurement Errors and Uncertainties, Springer New York, New York, NY, 2006. http://link.springer.com/10.1007/0-387-29143-1 (accessed August 28, 2016).

[46]F. Amiot, M. Bornert, P. Doumalin, J.-C. Dupré, M. Fazzini, J.-J. Orteu, C. Poilâne, L. Robert, R. Rotinat, E. Toussaint, B. Wattrisse, J.S. Wienin, Assessment of Digital Image Correlation Measurement Accuracy in the Ultimate Error Regime: Main Results of a Collaborative Benchmark, 
Strain. 49 (2013) 483-496. https://doi.org/10.1111/str.12054.

[47]N. Limodin, A. El Bartali, L. Wang, J. Lachambre, J.-Y. Buffiere, E. Charkaluk, Application of $\mathrm{X}$-ray microtomography to study the influence of the casting microstructure upon the tensile behaviour of an Al-Si alloy, Nucl. Instrum. Methods Phys. Res. Sect. B Beam Interact. Mater. At. 324 (2014) 57-62. https://doi.org/10.1016/j.nimb.2013.07.034.

[48]A.E. Bartali, Apport des mesures de champs cinématiques à l'étude des micromécanismes d'endommagement en fatigue plastique d'un acier inoxydable duplex, phdthesis, Ecole Centrale de Lille, 2007. https://tel.archives-ouvertes.fr/tel-00254732/document (accessed August 28, 2016).

[49]S. Roux, F. Hild, P. Viot, D. Bernard, Three-dimensional image correlation from X-ray computed tomography of solid foam, Compos. Part Appl. Sci. Manuf. 39 (2008) 1253-1265. https://doi.org/10.1016/j.compositesa.2007.11.011.

[50]J.-C. Passieux, J.-N. Périé, High resolution digital image correlation using proper generalized decomposition: PGD-DIC, Int. J. Numer. Methods Eng. 92 (2012) 531-550. https://doi.org/10.1002/nme.4349.

[51]L.A. Gomes Perini, J.-C. Passieux, J.-N. Périé, A Multigrid PGD-based Algorithm for Volumetric Displacement Fields Measurements, Strain. $50 \quad$ (2014) 355-367. https://doi.org/10.1111/str.12099.

[52]C.-L. Chen, A. Richter, R.C. Thomson, Mechanical properties of intermetallic phases in multi-component Al-Si alloys using nanoindentation, Intermetallics. 17 (2009) 634-641. https://doi.org/10.1016/j.intermet.2009.02.003.

[53]C.-L. Chen, A. Richter, R.C. Thomson, Investigation of mechanical properties of intermetallic phases in multi-component Al-Si alloys using hot-stage nanoindentation, Intermetallics. 18 (2010) 499-508. https://doi.org/10.1016/j.intermet.2009.09.013.

[54]K. Gall, M. Horstemeyer, D.L. McDowell, J. Fan, Finite element analysis of the stress distributions near damaged Si particle clusters in cast Al-Si alloys, Mech. Mater. 32 (2000) 277-301. https://doi.org/10.1016/S0167-6636(00)00003-X.

[55]R. Prasannavenkatesan, J. Zhang, D.L. McDowell, G.B. Olson, H.-J. Jou, 3D modeling of subsurface fatigue crack nucleation potency of primary inclusions in heat treated and shot peened martensitic gear steels, Int. J. Fatigue. $31 \quad$ (2009) 1176-1189. https://doi.org/10.1016/j.ijfatigue.2008.12.001.

[56]Q.Y. Wang, C. Bathias, N. Kawagoishi, Q. Chen, Effect of inclusion on subsurface crack initiation and gigacycle fatigue strength, Int. J. Fatigue. 24 (2002) 1269-1274. https://doi.org/10.1016/S0142-1123(02)00037-3.

[57]J. Barrirero, M. Engstler, F. Mücklich, Atom Probe Analysis of Sr Distribution in AlSi Foundry Alloys, in: B.A. Sadler (Ed.), Light Met. 2013, John Wiley \& Sons, Inc., 2013: pp. 289-296. http://onlinelibrary.wiley.com/doi/10.1002/9781118663189.ch50/summary (accessed January 15, 2017).

[58]C.M. Dinnis, J.A. Taylor, A.K. Dahle, Iron-related porosity in $\mathrm{Al}-\mathrm{Si}-(\mathrm{Cu})$ foundry alloys, Mater. Sci. Eng. A. 425 (2006) 286-296. https://doi.org/10.1016/j.msea.2006.03.045.

[59]J.A. Taylor, The effect of iron in Al-Si casting alloys, in: Australian Foundry Institute (AFI), 2004: pp. 148-157. http://espace.library.uq.edu.au/view/UQ:100729 (accessed August 10, 2016).

[60]M.J. Caton, J.W. Jones, J.M. Boileau, J.E. Allison, The effect of solidification rate on the growth of small fatigue cracks in a cast 319-type aluminum alloy, Metall. Mater. Trans. A. 30 (1999) 3055-3068. https://doi.org/10.1007/s11661-999-0216-4. 
[61]K. Gall, N. Yang, M. Horstemeyer, D.L. McDowell, J. Fan, The debonding and fracture of Si particles during the fatigue of a cast Al-Si alloy, Metall. Mater. Trans. A. 30 (1999) 3079-3088. https://doi.org/10.1007/s11661-999-0218-2.

[62]T.O. Mbuya, Analysis of microstructure and fatigue micromechanisms in cast aluminium piston alloys, phd, University of Southampton, 2011. http://eprints.soton.ac.uk/348998/ (accessed August 10, 2016).

[63]J.K. Miller, R. Delos, Initiation and Short Crack Behaviour in Aluminium Alloy Castings, in The Behaviour of Short Fatigue Cracks, Mech. Eng. Publ. (1986) 215.

[64]S. Joseph, S. Kumar, V.S. Bhadram, C. Narayana, Stress states in individual Si particles of a cast Al-Si alloy: Micro-Raman analysis and microstructure based modeling, J. Alloys Compd. 625 (2015) 296-308. https://doi.org/10.1016/j.jallcom.2014.10.207.

[65]S. Joseph, S. Kumar, Finite Element Analysis of Stress Evolution in Al-Si Alloy, J. Mater. Eng. Perform. 24 (2015) 253-260. https://doi.org/10.1007/s11665-014-1288-x.

[66]M.G. Mueller, G. Žagar, A. Mortensen, In-situ strength of individual silicon particles within an aluminium casting alloy, Acta Mater. $143 \quad$ (2018) 67-76. https://doi.org/10.1016/j.actamat.2017.09.058. 